\title{
Article
}

\section{Low pH enhances the action of maximin H5 against Staphylococcus aureus and helps mediate lysylated phosphatidylglycerol induced resistance}

Dennison, Sarah Rachel, Morton, Leslie Hugh Glyn, Harris, Frederick and Phoenix, David Andrew

Available at https://clok.uclan.ac.uk/14888/

Dennison, Sarah Rachel orcid iconORCID: 0000-0003-4863-9607, Morton, Leslie Hugh Glyn, Harris, Frederick and Phoenix, David Andrew (2016) Low pH enhances the action of maximin H5 against Staphylococcus aureus and helps mediate lysylated phosphatidylglycerol induced resistance. Biochemistry, 55 (7). pp. 3735-3751. ISSN 0006-2960

It is advisable to refer to the publisher's version if you intend to cite from the work. http://dx.doi.org/10.1021/acs.biochem.6b00101

For more information about UCLan's research in this area go to http://www.uclan.ac.uk/researchgroups/ and search for < name of research Group>.

For information about Research generally at UCLan please go to http://www.uclan.ac.uk/research/

All outputs in CLoK are protected by Intellectual Property Rights law, including Copyright law. Copyright, IPR and Moral Rights for the works on this site are retained by the individual authors and/or other copyright owners. Terms and conditions for use of this material are defined in the policies page. 


\section{Low pH enhances the action of maximin H5}

\section{against Staphylococcus aureus and helps mediate}

\section{lysylated phosphatidylglycerol induced resistance}

Sarah R. Dennison ${ }^{a}$, Leslie HG Morton ${ }^{b}$, Frederick Harris ${ }^{b}$ and David A. Phoenix ${ }^{c^{*}}$

AUTHOR ADDRESS aschool of Pharmacy and Biomedical Sciences, University of Central Lancashire Preston, PR1 2HE, UK.

${ }^{b}$ School of Forensic and Investigative Science, University of Central Lancashire Preston, PR1 2HE, UK.

'School of Applied Science, London South Bank University, 103 Borough Road, London SE1 OAA, UK

\section{CORRESPONDING AUTHOR FOOTNOTE}

Prof D A Phoenix, Office of the Vice Chancellor, London South Bank University, 103 Borough Road, London SE1 0AA, UK.

Phone: +44 (0) 207815 6001, Fax: +44 (0) 207815 6099, E-mail: phoenixd@lsbu.ac.uk

\section{Author Contributions}

The manuscript was written through contributions of all authors. All authors have given approval to the final version of the manuscript. 


\section{Abbreviations and Textual Footnotes}

AMP, antimicrobial peptide; CD, circular dichroism; CL, cardiolipin; $\mathrm{C}_{\mathrm{s}}{ }^{-1}$, compressibility modulus; CM, cytoplasmic membrane; DOPG, 1,2-dioleoyl-sn-glycero-3-phospho-(1'-racglycerol); $E_{\max }$, maximal levels of lysis; $\Delta \mathrm{G}_{\mathrm{mix}}$, Gibbs free energy of mixing; $\mu_{\mathrm{H}}$, hydrophobic moment; $<\mathrm{H}>$ mean hydrophobicity; Lys-PG, lysylated phosphatidylglycerol; Km, lipid affinity; Lys-DOPG, 1,2-dioleoyl-sn-glycero-3-[phospho-rac-(3-lysyl(1-glycerol))]; MH5, Maximin H5; MIC, minimum inhibitory concentration, PE, phosphatidylethanolamine; PG, phosphatidylglycerol; PMF, proton motive force; SUVs, Small unilamellar vesicles.

KEYWORDS Antimicrobial peptide, lysylated phosphatidylglycerol, monolayer interactions, pH effect, Staphylococcus aureus, 
ABSTRACT Maximin H5 (MH5) is an amphibian antimicrobial peptide specifically targeting Staphylococcus aureus. At $\mathrm{pH} 6$, the peptide showed an increased ability to penetrate $(\Delta \Pi=6.2$ $\mathrm{mN} \mathrm{m}^{-1}$ ) and lyse (lysis $\left.=48 \%\right)$ S. aureus membrane mimics, which incorporated physiological levels of lysylated phosphatidylglycerol (Lys-PG, $60 \%)$ as compared to $\mathrm{pH} 7\left(\Delta \Pi=5.6 \mathrm{mN} \mathrm{m}^{-1}\right.$ and lysis $=40 \%$ at pH 7) where levels of Lys-PG are lower (40\%). The peptide therefore appears to have optimal function at $\mathrm{pH}$ levels known to be optimal for the organism's growth. MH5 killed S. aureus (minimum inhibitory concentration $=90 \mu \mathrm{M}$ ) via membranolytic mechanisms that involved the stabilization of $\alpha$-helical structure (circa $45-50 \%$ ) and which showed similarities to the 'Carpet' mechanism based on its ability to increase the rigidity $\left(\mathrm{C}_{\mathrm{s}}^{-1}=109.94 \mathrm{mN} \mathrm{m}^{-1}\right)$ and thermodynamic stability $\left(\Delta \mathrm{G}_{\mathrm{mix}}=-3.0\right)$ of physiologically relevant $S$. aureus membrane mimics at $\mathrm{pH}$ 6. Based on theoretical analysis this mechanism may involve the use of a tilted peptide structure and efficacy was noted to vary inversely with the Lys-PG content of S. aureus membrane mimics for each $\mathrm{pH}$ studied ( $\mathrm{R}^{2}$ circa 0.97$)$, which led to the suggestion that under biologically relevant conditions, low $\mathrm{pH}$ helps mediate Lys-PG induced resistance in S. aureus to MH5 antibacterial action. The peptide showed a lack of haemolytic activity ( $<2 \%$ haemolysis) and merits further investigation as a potential template for development as an anti-staphylococcal agent in medically and biotechnically relevant areas. 
Many amphibians secrete a wide range of antimicrobial peptides (AMPs) and other biologically active compounds to protect the skin from bacterial infection ${ }^{1,2}$ and these peptides have the potential for further commercial development, including roles as anti-infective, anticancer, antiviral and anti-diabetic agents ${ }^{3-6}$. For example, maximin H5 (MH5) is an anionic peptide that belongs to a family of AMPs identified in the skin secretions of the Chinese red belly toad, Bombina maxima ${ }^{7}$ and in the brain of both $B$. maxima and other toads of the same genus ${ }^{8}$. Several studies have shown MH5 to be effective against Staphylococcus aureus but it exhibited no activity against other Gram-positive bacteria, Gram-negative bacteria, fungi or enveloped viruses ${ }^{7,9}$. More recent work has suggested that that the peptide penetrates and disrupts membranes via the adoption of a tilted structure ${ }^{10}$ and is rendered inactive against Escherichia coli via a novel resistance mechanism involving phosphatidylethanolamine (PE) binding ${ }^{11}$. Essentially, charge-charge interactions together with a hydrogen bonding network between MH5 and PE in the cytoplasmic membrane (CM) of $E$. coli anchor the peptide to the bilayer surface thereby inhibiting its membranolytic action ${ }^{11,12}$.

It is generally accepted that the interaction with the CM of target bacteria is an essential step in the antimicrobial action of AMPs ${ }^{13-17}$ and interactions of this type have been investigated using a variety of model membranes ${ }^{18-23}$. These model membranes are usually formed from lipid mixtures with a head-group composition that reflects the molar ratio of the major lipids in the bacterial membrane, namely PE, phosphatidylglycerol (PG), Lys-PG and cardiolipin (CL). The CMs of Gram-negative bacteria are primarily composed of PE, such as that of E. coli, which typically contains approximately 80 \% PE, 6 \% PG and $12 \%$ CL at neutral pH. In contrast, the CMs of Gram-positive bacteria are mainly composed of lipids derived from PG, exemplified by that of $S$. aureus, which typically contains circa 55 \% PG, 40 \% Lys-PG and $5 \%$ CL at neutral pH ${ }^{14,15,}$ 
24. In general, anionic lipids constitute over $80 \%$ of the total lipid found in the membranes of Gram-positive bacteria but less than $30 \%$ of the total lipid present in those of Gram-negative bacteria ${ }^{15}$. These varying levels of anionic lipid are thought to contribute to the differing bacterial specificities shown across AMPs ${ }^{25,26}$, which are generally cationic and target the cells of bacteria via electrostatic interactions with negatively charged components of the $\mathrm{CM}^{13-15,17}$.

In contrast to anionic lipids of the CM, it is well established that the cationic lipid, Lys-PG, helps to provide $S$. aureus with a major mechanism of resistance to AMPs and also helps deal with environmental stresses that are optimal for the growth of the organism particularly under the low $\mathrm{pH}$ conditions ${ }^{27-30}$. According to this mechanism of resistance, cationic AMPs activate a sensor histidine kinase (ApsS) of the ApsSR (GraSR) regulon, which leads to the up-regulated expression of the virulence factor $m p r F$. The protein product of this gene, mprF, is a Lys-PG synthase that catalyses the transfer of lysine from lysyl-tRNA to the PG head-group and flipping of the resulting Lys-PG to the outer leaflet of the $S$. aureus $\mathrm{CM}^{23,31-34}$. The presence of the lipid in the CM of $S$. aureus attenuates a number of membrane associated properties that inhibit the ability of cationic AMPs to bind and exert their membranolytic action against these membranes $27,28,31,33-38$. This effect in enhanced by low pH conditions, when the production of Lys-PG is upregulated and where levels of the Lys-PG as high as $80 \%$ of total membrane lipid have been reported for the organism 29, 39-42.

In general, the role of Lys-PG in mediating resistance to cationic AMPs in S. aureus has been well characterised $27,31,33,35,43-45$ but there is limited information on what if any role this mechanism of resistance has against anionic AMPs ${ }^{46-48}$. Accordingly, here, we have characterised the action of MH5 against S. aureus and investigated the role of Lys-PG its activity. Our results show that MH5 adopts lipid interactive $\alpha$-helical structure and kills $S$. aureus via a membranolytic 
mode of action that is similar to the 'Carpet mechanism' and furthermore, activity is enhanced by low $\mathrm{pH}$. However, our results also suggest that the action of MH5 is attenuated by the presence of Lys-PG in the CM of the organism, which inhibits insertion by the peptide through membrane stabilization and lipid packing effects.

\section{EXPERIMENTAL PROCEDURES}

Materials - The peptide homologue of maximin H5, MH5 (ILGPVLGLVSDTLDDVLGIL$\mathrm{NH}_{2}$ ) to purity greater than $95 \%$ was purchased from Pepceuticals (Leicestershire, UK). Solvents and phospholipids including: cardiolipin (CL); 1,2-dioleoyl-sn-glycero-3-phospho-(1'-racglycerol) (DOPG); and 1,2-dioleoyl-sn-glycero-3-[phospho-rac-(3-lysyl(1-glycerol))] (LysDOPG) were purchased from Avanti Polar Lipids (Alabaster, AL) and were used without further purification. Solvents were obtained from VWR (HPLC grade) and unless otherwise stated, all other regents were purchased from SIGMA-ALDRICH (UK).

The antibacterial properties of MH5 - Cultures of S. aureus, strain UL12, which had been freezedried in $20 \%(\mathrm{v} / \mathrm{v})$ glycerol and stored at $-80^{\circ} \mathrm{C}$, were used to inoculate $10 \mathrm{ml}$ aliquots of sterile Nutrient broth and incubated at $37{ }^{\circ} \mathrm{C}$ until the exponential phase $(\mathrm{OD}=0.6 ; \lambda=600 \mathrm{~nm})$ was reached. Using a bench top centrifuge, these cell suspensions were centrifuged at 15,000 $\times$ g at 4 ${ }^{\circ} \mathrm{C}$ for 10 minutes. The resulting pellet was washed three times in $25 \%$ Ringer's solution and then resuspended in $500 \mu \mathrm{l}$ of the same medium. Aliquots $(10 \mu \mathrm{l})$ of these cell suspensions were then used to inoculate samples of MH5, which were solubilised in $25 \%$ strength Ringer's solution 
(0 $\mu \mathrm{M}$ to $1000 \mu \mathrm{M})$, and incubated at $37^{\circ} \mathrm{C}$ overnight. After incubation, each bacterial culture was streaked on to a nutrient agar plated and incubated at $37^{\circ} \mathrm{C}$ for $12 \mathrm{~h}$.

Total lipid extracts from cells of S. aureus - Lipid extracts from membranes of S. aureus were prepared using a protocol based on the technique of Bligh and Dyer ${ }^{49}$. Essentially, bacterial cultures were grown, washed and resuspended in $500 \mu$ of $25 \%$ strength Ringer's solution, all as described above. These cell suspensions were then vortexed with $1.5 \mathrm{ml}$ of chloroform: methanol (2:1) for 5 minutes, water $(500 \mu \mathrm{l})$ was then added and the whole vortexed for 5 minutes before being centrifuged at low speed $(660 \times \mathrm{g}, 5 \mathrm{~min})$ to produce two phases. The lower organic layer was concentrated by removing the solvent with $\mathrm{N}_{2}$ (g).

Theoretical analyses of MH5 - The potential of MH5 to form a membrane interactive $\alpha$-helix was determined using the hydrophobic moment methodology of Eisenberg et al., ${ }^{50,51}$. According to this methodology, the hydrophobicity of successive amino acids in a protein sequence are treated as vectors and summed in two dimensions, assuming an amino acid side chain periodicity of $100^{\circ}$. This summation leads to the mean hydrophobic moment, $\left\langle\mu_{\mathrm{H}}\right\rangle$, which provides a measure of $\alpha$ helix amphiphilicity. Using the normalised consensus hydrophobicity scale of Eisenberg et al., 52 and a moving window of 11 residues, the window in the sequence of MH5 with the highest value of $<\mu_{\mathrm{H}}>$ was computed along with its mean hydrophobicity, $<\mathrm{H}>$. Using these values of $<\mu_{\mathrm{H}}>$ and $<\mathrm{H}>$ as coordinates, a data point representing MH5 was plotted on the hydrophobic moment plot diagram of Eisenberg et al. ${ }^{50}$, as modified by Harris et al. ${ }^{53}$, to identify candidate tilted $\alpha$ helix forming segments. Graphical representation of MH5 as a two-dimensional axial projection 
taken perpendicular to the helical long axis and assuming an amino acid periodicity of $100^{\circ}$ was undertaken according to the methodology of Schiffer and Edmundson ${ }^{54}$.

The structural determination of MH5- Small unilamellar vesicle (SUVs) were prepared from either lipid extracts of S. aureus membranes or CL, DOPG, Lys-DOPG, or DOPG:CL:Lys-DOPG in the molar ratio 55:5:X where $X=0,20,40,60,80$ or 100 . These single lipids and lipid mixtures were dissolved separately in chloroform and dried under $\mathrm{N}_{2}(\mathrm{~g})$ before being placed under vacuum for 4 hours. The resulting lipid films were rehydrated using $1 \times$ phosphate buffered saline (PBS) at $\mathrm{pH}$ values of either $\mathrm{pH}$ 6, $\mathrm{pH} 7$ or $\mathrm{pH} 8$, sonicated for an hour or until the solution was no longer turbid, and then subjected to 5 cycles of freeze-thawing. MH5 $\left(0.1 \mathrm{mg} \mathrm{ml}^{-1}\right)$ was then solubilised in these SUVs to give a peptide to lipid ratio of 1:100 and these samples used for circular dichroism (CD) analysis. These analyses were performed using a J-815 spectropolarimeter (Jasco, UK) at $20^{\circ} \mathrm{C}$, all as previously described ${ }^{55}$. Far-UV CD spectra were collated, for MH5 in the presence and absence of lipid. Four scans per sample were performed using a $10 \mathrm{~mm}$ path-length cell, over a wavelength range 260 to $180 \mathrm{~nm}$ at $0.5 \mathrm{~nm}$ intervals using a band width of $1 \mathrm{~nm}$ and a scan speed $50 \mathrm{~nm} \mathrm{~min}{ }^{-1}$. For all spectra acquired, the baseline acquired in the absence of peptide was subtracted ${ }^{56}$. The percentage $\alpha$-helical content was estimated using the CDSSTR method (protein reference set 3) from the DichroWeb server ${ }^{57-59}$. These experiments were repeated in quintuplicate and the percentage $\alpha$ - helicity was averaged.

Langmuir trough analysis of MH5 - All monolayer experiments were performed at room temperature $\left(20^{\circ} \mathrm{C}\right)$ using a Teflon $601 \mathrm{M}$ Langmuir Blodgett trough (Biolin Scientific KSV NIMA, UK) equipped with moveable barriers and the surface pressure measured using a Wilhelmy 
plate made of Whatman's CH1 filter paper, all as previously described ${ }^{11}$. In all experiments, the trough subphase consisted of PBS prepared with Milli-Q-water (resistivity $\approx 18 \mathrm{M} \Omega \mathrm{cm}$ ) and was at $\mathrm{pH}$ values of either 6,7 or 8.

The surface activity of MH5 - To determine the surface activity of MH5, the peptide was injected into the Langmuir trough PBS subphase at $\mathrm{pH}$ values of either $\mathrm{pH}$ 6, $\mathrm{pH} 7$ or $\mathrm{pH} 8$ via an injection port using a Hamilton syringe to give final MH5 concentrations ranging between 1.0 and $18 \mu \mathrm{M}$. After injection, the maximal surface pressures induced by the peptide were recorded as a function of the final MH5 concentration in the subphase. Each experiment was repeated in quintuplicate and the mean taken.

To determine the interfacial orientation of MH5, chloroformic solutions of the peptide $(1.5 \times$ $10^{15}$ molecules) were spread onto the Langmuir trough PBS subphase at $\mathrm{pH}$ values of either $\mathrm{pH}$, $\mathrm{pH} 7$ or $\mathrm{pH}$ 8. In each case, the peptide film was allowed to stabilize for 10 minutes and the trough barriers compressed at a constant speed of $0.33 \mathrm{~nm}^{2} \mathrm{~min}^{-1}$ until the collapse pressure was achieved. Each experiment was repeated in quintuplicate and the mean value taken.

The interaction of MH5 with lipid monolayers - Monolayers were formed by spreading the chloroformic solutions of lipid onto the Langmuir trough PBS subphase at $\mathrm{pH}$ values of either $\mathrm{pH}$ 6, pH 7 or $\mathrm{pH}$ 8. These chloroformic solutions contained either lipid extracts of membranes of $S$. aureus or CL, DOPG, Lys-DOPG or DOPG:CL:Lys-DOPG in the molar ratio 55:5:X where $\mathrm{X}=$ $0,20,40,60,80$ or 100 . The trough barriers were closed at a rate of $5 \mathrm{~cm}^{2} \mathrm{~min}^{-1}$ until a starting pressure of $30 \mathrm{mN} \mathrm{m}^{-1}$ was achieved, which is generally taken as that of naturally occurring membranes ${ }^{60}$. Monolayers were allowed to equilibrate for 30 minutes and using a Hamilton 
syringe, MH5 was injected into the trough subphase without disruption of the monolayer to give a final peptide concentration of $2.0 \mu \mathrm{M}$. The subphase was continuously mixed with a magnetic stirrer at $5 \mathrm{rpm}$, each experiment repeated in quintuplicate and the mean value taken.

For compression isotherm analysis, monolayers were formed by spreading chloroformic solutions of lipid (2.6 x $10^{15}$ molecules) onto the Langmuir trough PBS subphase at $\mathrm{pH}$ values of either $\mathrm{pH}$ 6, $\mathrm{pH} 7$ or $\mathrm{pH}$ 8. These chloroformic solutions contained either CL, DOPG, Lys-DOPG or DOPG:CL:Lys-DOPG in the molar ratio 55:5:X where $\mathrm{X}=0$, 20, 40, 60, 80 or 100. These lipid monolayers were allowed to settle for $30 \mathrm{~min}$ and the trough barriers were closed at a rate of 0.22 $\mathrm{nm}^{2} \min ^{-1}$ until the monolayer collapse pressure was achieved. These experiments were then repeated with MH5 in the trough PBS subphase after introduction via an injection port using a Hamilton syringe to give a final peptide concentration of $8 \mu \mathrm{M}$. The compressibility modulus $\left(\mathrm{C}_{s}{ }^{-}\right.$ ${ }^{1}$ ) at each of the experimental mixing ratios was then calculated by applying the following equation 61.

$$
C_{s}^{-1}=-A\left(\frac{\delta \pi}{\delta A}\right)
$$

where $\mathrm{A}$ is the area per molecule at a given surface pressure $(\pi)$.

Using these isotherms, the thermodynamic stability of monolayers was then investigated by applying the Gibbs equation:

$$
\Delta G_{\text {mix }}=\int\left[A_{12}-\left(X_{1} A_{1}+X_{2} A_{2}\right) d \pi\right.
$$

where $A_{1,2, \ldots n}$ is the molecular area occupied by the mixed monolayer, $A_{1}, A_{2} \ldots A_{n}$ are the area per molecule in the pure monolayers of component $1,2, \ldots \mathrm{n}, X_{1}, X_{2} \ldots \mathrm{X}_{n}$ are the molar fractions of the 
components and $\pi$ is the surface pressure. Numerical data were calculated from the compression isotherms according to the mathematical method of Simpson ${ }^{62}$.

The lytic activity of MH5 - To determine the lytic ability of MH5, chloroformic solutions were prepared from either lipid extracts of S. aureus membranes, or DOPG:CL:Lys-DOPG in the molar ratio 55:5:X where $X=0,20,40,60,80$ or 100 . These various lipid solutions were taken and the chloroform evaporated off under a stream of nitrogen before further drying under vacuum for 1 hour to form a thin film. The lipid film was then hydrated with $1 \mathrm{ml}$ of $5.0 \mathrm{mM}$ HEPES containing $70 \mathrm{mM}$ calcein at either $\mathrm{pH} 6,7$ or 8 . The resulting suspension was vortexed for 5 minutes, sonicated for 30 minutes and then subjected to 3 cycles of freeze-thawing. Liposomes were extruded 11 times through a $0.1 \mu$ m polycarbonate filter using an Avanti polar lipids min-extruder apparatus. Calcein entrapped vesicles were separated from free calcein by gel filtration using a Sephadex G75 column (SIGMA-ALDRICH (UK)), which was rehydrated overnight in $20 \mathrm{mM}$ HEPES, $150 \mathrm{mM} \mathrm{NaCl}$ and $1.0 \mathrm{mM}$ EDTA at either $\mathrm{pH}$ 6, 7 or 8 . The column was eluted with 5 mM HEPES either $\mathrm{pH}$ 6, 7 or 8.

The calcein release assay was performed by combining $2 \mathrm{ml}$ of $20 \mathrm{mM}$ HEPES, $150 \mathrm{mM} \mathrm{NaCl}$ and 1.0 mM EDTA with $20 \mu \mathrm{l}$ calcein vesicles at either $\mathrm{pH} 6,7$ or 8 . MH5 was then added to these mixtures to give final peptide concentrations ranging from 0 to $1 \mathrm{mM}$ and the whole incubated for 2 hours at room temperature $\left(20^{\circ} \mathrm{C}\right)$. The fluorescence intensities of calcein were measured using an FP-6500 spectrofluorometer (Jasco, UK), with an excitation wavelength of 490 $\mathrm{nm}$ and an emission wavelength of $520 \mathrm{~nm}$. To measure maximum fluorescence, $20 \mu \mathrm{l}$ of Triton 
$\times 100$ was used to dissolve the vesicles. Each experiment was repeated in quintuplicate and the mean percentage of dye leakage was then calculated taken.

The haemolytic properties of MH5 - The activity of the peptide against ovine erythrocytes was determined as previously described ${ }^{63}$. Essentially, these erythrocytes $(3 \mathrm{ml})$ were taken and washed three times with PBS (35 mM phosphate buffered saline, $0.15 \mathrm{M} \mathrm{NaCl}, \mathrm{pH} 7.4$ ) by centrifugation $(1,200 \times \mathrm{g}, 5 \mathrm{~min})$ until the supernatant was clear. Washed erythrocytes were then resuspended in PBS to a final volume of $20 \mathrm{ml}$. Solutions $(10 \mu \mathrm{l})$ containing MH5 at appropriate concentrations were added to suspension of washed erythrocytes $(190 \mu \mathrm{l})$ and were incubated for $1 \mathrm{~h}$ at $37^{\circ} \mathrm{C}$. The samples were then centrifuged $(12,000 \times \mathrm{g}, 5 \mathrm{~min})$. The release of haemoglobin was monitored by diluting $100 \mu \mathrm{l}$ of supernatant with $900 \mu \mathrm{PBS}$ and absorbance measured at 576 nm. For negative and positive controls, PBS buffer $\left[A_{\mathrm{PBS}}\right]$ and $0.1 \%$ Triton X-100 $\left[A_{\text {Triton }}\right]$ were used. The percentage haemolysis was calculated according to the following equation:

$$
\text { Percentage haemolysis }=\left[A_{\text {Peptide }}\right]-\left[A_{\mathrm{PBS}}\right] /\left[A_{\text {Triton }}\right]-\left[A_{\mathrm{PBS}}\right] \times 100 \text {. }
$$

In all cases, values of the \% haemolysis were determined in quadruplicate and the mean value derived.

\section{RESULTS}

The antimicrobial properties of MH5 - The peptide belongs to a suite of AMPs that are known to have activity against a variety of prokaryotic microorganisms ${ }^{7,8}$ and during the course of this investigation the peptide was tested against strains of $S$. aureus using a standard antimicrobial 
assay. After 12 hours of incubation with the organism, MH5 exhibited activity against S. aureus with a minimum inhibitory concentration (MIC) of $90 \mu \mathrm{M}$.

Theoretical analyses of MH5 - The sequence of MH5 was analysed according to hydrophobic moment plot methodology and was found to exhibit an amphiphilicity of 0.44 , measured as $<\mu_{\mathrm{H}}$ $>$, and a hydrophobicity of 0.29 , quantified as $<\mathrm{H}>{ }^{64,65}$. Values of $<\mu_{\mathrm{H}}>$ with this order of magnitude have been reported for other anionic AMPs and are generally indicative of the potential to form $\alpha$-helical structure in an anisotropic environment with activity at an aqueous or membrane interface ${ }^{66}$. Using the values of $<\mu_{\mathrm{H}}>$ and $<\mathrm{H}>$ determined for MH5 as coordinates, this $\alpha$-helix was plotted on the extended hydrophobic moment plot diagram of Harris et al. ${ }^{53}$ and the location of the data point indicated the potential to form a tilted peptide with similar parameters to HA2, a viral fusion peptide and known tilted peptide (Figure 1A). Tilted peptides are a class of amphiphilic $\alpha$-helices that also possess a hydrophobicity gradient along the $\alpha$-helical long axis. This structural feature causes the $\alpha$-helix to penetrate membranes at a shallow angle of between $20^{\circ}$ and $80^{\circ}$, thereby promoting a range of membrane destabilizing effects including the disturbance of lipid organisation and the compromise of bilayer integrity ${ }^{14,67-71}$. To characterise the potential for tilted peptide formation, amphiphilic profiling of MH5 was undertaken, which essentially visualises potential hydrophobicity gradients via plots of $-<\mu_{\mathrm{H}}>$ along a peptide’s sequence ${ }^{72}$. This analysis revealed that MH5 possessed a strong hydrophobicity gradient, which decreased in the direction of the $\mathrm{N}$ terminus to the $\mathrm{C}$ terminus and extended over most of the peptide's primary structure (Figure 1B). MH5 was then represented as a two-dimensional axial projection, assuming a residue periodicity of $100^{\circ}{ }^{54}$ and this $\alpha$-helix showed well defined amphiphilicity (Figure 1C). Consistent 
with the ability to form a tilted peptide, the MH5 $\alpha$-helix possessed a wide apolar face, predominantly formed from strongly hydrophobic residues such as leucine, isoleucine and valine (Figure 1C). The $\alpha$-helix possessed a narrower polar face with multiple glycine residues and a triplet of aspartic acid residues, which rendered this $\alpha$-helical face strongly anionic. These residues, D11, D14 and D15, essentially define the polar face of the MH5 $\alpha$-helix and are centrally clustered in relation to the long axis of this $\alpha$-helix (Figure 1C). The M5 $\alpha$-helix showed structural similarities to that of HA2, which also includes a wide apolar face formed from strongly hydrophobic residues and a narrower anionic polar face with multiple glycine residues (Figure 1C). It is believed that the lack of charge and conformational flexibility provided by glycine residues plays an important role in facilitating the oblique membrane insertion of tilted peptides ${ }^{14}$, 67-71.

The surface activity of MH5 - Amphiphilic AMPs are generally highly surface active ${ }^{18,22}$ and here, MH5 was investigated for such activity at an air / buffer interface (Figure 2A). It was found that at $\mathrm{pH}$ 6, $\mathrm{pH} 7$ and $\mathrm{pH}$ 8, the surface pressure changes induced by the peptide increased rapidly up to concentrations of $2 \mu \mathrm{M}$. Above this concentration, surface pressure became independent of MH5 levels, indicating that the air / buffer interface was saturated with molecules of the peptide. These surface pressure changes were maximal at $\mathrm{pH} 6$ with a value of $28.0 \mathrm{mN} \mathrm{m}^{-1}$ and dropped to $26.0 \mathrm{mN} \mathrm{m}^{-1}$ at $\mathrm{pH}$ 8, indicating that $\mathrm{MH} 5$ possesses generally high surface activity, which was enhanced by acid conditions (Figure 2A). Saturation surface pressures of this order are generally characteristic of peptides with membrane interactive structure, such as AMPs ${ }^{73,74}$. 
The orientation of MH5 at an air / buffer interface was investigated using compression isotherms and it was found that at $\mathrm{pH}$ 6, $\mathrm{pH} 7$ and $\mathrm{pH}$ 8, these isotherms have a generally sigmoidal shape indicating that the peptide forms stable monolayers (Figure 2B) ${ }^{18,22}$. Under compression, these monolayers showed collapse surface pressures that indicated the presence of well-ordered peptide films with a maximal value of $26.8 \mathrm{mN} \mathrm{m}^{-1}$ at $\mathrm{pH} 6$, which dropped to $24.1 \mathrm{mN} \mathrm{m}^{-1}$ at $\mathrm{pH} 8^{75}$. The corresponding surface areas per molecule of MH5 ranged between $1.9 \mathrm{~nm}^{2}$ and $1.6 \mathrm{~nm}^{2}$, which is comparable to that reported for other AMPs, such as aurein 2.5 (Figure 2B) ${ }^{76}$, and would be expected if MH5 were in an $\alpha$-helical conformation, orientated perpendicular to the interface ${ }^{77}$.

The extrapolated area at $\Pi=0 \mathrm{mN} \mathrm{m}^{-1}$ for these isotherms provides a measure of the mean monolayer surface area per MH5 molecule and it was found that this area is maximal at pH 6 with a value $4.5 \mathrm{~nm}^{2}$ which drops to $4.1 \mathrm{~nm}^{2}$ at $\mathrm{pH} 8$ (Figure 2B). Mean molecular areas of this order are comparable to those reported for other AMPs ${ }^{78}$ and would be expected for MH5 in an $\alpha$-helical conformation that was orientated parallel to the interface ${ }^{79}$. In combination, these results imply that under all the $\mathrm{pH}$ conditions studied here, the amphiphilic characteristics possessed by MH5 in an $\alpha$-helical conformation are able to influence the orientation of the peptide in the anisotropic environment provided by an interface.

Secondary structure of MH5 in the presence of lipid mimics of S. aureus membranes - The conformational behaviour of $\mathrm{MH} 5$ was studied and at $\mathrm{pH}$ 6, $\mathrm{pH} 7$ and $\mathrm{pH}$ 8, and in aqueous solution the peptide was predominantly formed from $\beta$-strands, $\beta$-turns and unordered structure, consistent with previous reports ${ }^{11}$. However, in the presence of SUVs formed from lipid extracts of S. aureus membranes, at pH 6, pH 7 and $\mathrm{pH}$ 8, CD spectra showed minima at $221-222$ and $209-210 \mathrm{~nm}$ 
(Figure 3), which is indicative of $\alpha$-helical structure in MH5 ${ }^{55}$. Analysis of these CD spectra revealed that the levels of $\alpha$-helicity were around $48 \%$ at $\mathrm{pH} 8$, but increased to $58 \%$ as $\mathrm{pH}$ was decreased to $\mathrm{pH}$ 6, showing clearly that MH5 is able to form an $\alpha$-helical structure in the presence of an asymmetric interface that is enhanced by low $\mathrm{pH}$ (Table 1).

To form lipid mimics of $S$. aureus membranes with known compositions, SUVs were constructed from DOPG:CL:Lys-DOPG in the molar ratio 55:5:X where $\mathrm{X}=0$, 20, 40, 60, 80 or 100, and the conformational behaviour of MH5 in the presence of these lipid bodies investigated (Figure 4). For a given value of $\mathrm{X}$, it was found that the peptide adopted $\alpha$-helical structure in a $\mathrm{pH}$ dependent manner that closely mimicked that observed for MH5 in the case of SUVs formed from lipid extracts of $S$. aureus membranes (Table 1). These observations confirmed that synthetic lipid mixes were able to simulate the naturally occurring membranes of $S$. aureus, which were then used to investigate the influence of Lys-DOPG levels in these membranes on the conformational behaviour of $\mathrm{MH} 5$ at $\mathrm{pH}$ 6, $\mathrm{pH} 7$ and $\mathrm{pH}$ 8. For each $\mathrm{pH}$ studied, it was found that MH5 was predominantly $\alpha$-helical and possessed similar levels of this structure for all values of X (Figure 4). However, for a given level of $\mathrm{X}$, a statistically significant difference in levels of MH5 $\alpha$-helicity was observed as pH was varied (Figure 4B), decreasing from circa $50 \%$ at pH 6 to $\operatorname{circa} 40 \%$ at pH 8 [F = 98.376; $\mathrm{p}=0.001]$. In relation to physiological levels of the lipid in membranes of $S$. aureus, which are typically $\mathrm{X}=60$ at $\mathrm{pH}$, and $\mathrm{X}=40$ at $\mathrm{pH} 7^{29,39-42}$, MH5 possessed levels of $\alpha$-helicity of circa $45 \%$ at pH $7(\mathrm{X}=40)$, which increased by around $5 \%$ at pH $6(\mathrm{X}=60)$ (Figure 4B). These results indicate that the levels of $\alpha$-helicity possessed by MH5 were enhanced by low pH conditions with varying Lys-DOPG having limited influence on $\alpha$-helicity. 
The interaction of MH5 with lipid mimics of S. aureus membranes - The levels of amphiphilicity predicted for MH5 are consistent with membrane interactive potential (Figure 1) and lipid monolayers formed from lipid extracts of $S$. aureus membranes were used to investigate this potential at $\mathrm{pH}$ 6, $\mathrm{pH} 7$ and $\mathrm{pH} 8$ (Figure 5A). At each $\mathrm{pH}$ studied, the peptide rapidly induced pressure changes in these monolayers until they became saturated with $\mathrm{MH} 5$. At pH 7 and $\mathrm{pH}$ 8, MH5 partitioned into these monolayers, inducing maximal surface pressure changes of circa 4.0 $\mathrm{mN} \mathrm{m}^{-1}$ to $3.5 \mathrm{mN} \mathrm{m}^{-1}$ over 400 seconds. However, at $\mathrm{pH}$ 6, MH5 induced maximal surface pressures in monolayers of the order of $8.0 \mathrm{mN} \mathrm{m}^{-1}$ over 120 seconds, showing clearly that the ability of the peptide to partition into lipid mimics of $S$. aureus membranes monolayers was enhanced by low pH conditions (Figure 5A).

Monolayers formed from lipid mimics of $S$. aureus membranes with known compositions were constructed from DOPG:CL:Lys-DOPG in the molar ratio 55:5: $X$ where $X=0,20,40,60,80$ or 100, and were used to investigate the influence of varying Lys-DOPG levels on the membrane interactions of $\mathrm{MH} 5$ at $\mathrm{pH}$ 6, $\mathrm{pH} 7$ and $\mathrm{pH} 8$ (Figure 5B). For each pH studied, it was found that the maximal pressure change induced by the peptide showed a strong negative correlation with X, which was $\mathrm{R}^{2}=0.95$ at $\mathrm{pH} 6,0.97$ at $\mathrm{pH} 7$ and 0.99 at $\mathrm{pH}$ 8. This inverse correlation shows clearly that the presence of Lys-DOPG in lipid mimics of S. aureus membranes is able to inhibit the ability of MH5 to insert into these membranes. However, for a given level of X, the ability of MH5 to partition into membranes was observed to vary with $\mathrm{pH}$, for example, at $\mathrm{X}=20$, the pressure changes induced by the peptide decreased from $7.4 \mathrm{mN} \mathrm{m}^{-1}$ at $\mathrm{pH} 6$ to $6.15 \mathrm{mN} \mathrm{m}^{-1}$ at $\mathrm{pH} 8$ (Figure 5B), In relation to physiological levels of Lys-DOPG in membranes of S. aureus, MH5 induced maximal surface pressure changes of $5.6 \mathrm{mN} \mathrm{m}^{-1}$ at $\mathrm{pH} 7(\mathrm{X}=40)$, which increased to $6.2 \mathrm{mN} \mathrm{m}^{-}$ 
${ }^{1}$ at $\mathrm{pH} 6(\mathrm{X}=60)$ (Figure $\left.5 \mathrm{~B}\right)$. These results clearly indicate that the ability of the peptide to partition into $S$. aureus membranes is enhanced by low $\mathrm{pH}$ conditions.

Thermodynamic analysis of MH5 interactions with lipid mimics of S. aureus membranes Monolayers were constructed from DOPG:CL:Lys-DOPG in the molar ratio 55:5:X where $\mathrm{X}=0$, 20, 40, 60 or 80 , and were compressed in the presence and absence of MH5 to produce isotherms at pH 6, pH 7 and pH 8 (Figure 6). For each of these experimental systems, the isotherms produced were then used to derive values for $\mathrm{C}_{\mathrm{s}}^{-1}$, the compressibility modulus, at $20 \mathrm{mN} \mathrm{m}^{-1}$ (Table 2). It was found that at each $\mathrm{pH}$ studied, in the absence of $\mathrm{MH} 5$, increasing $\mathrm{X}$ led to elevations in the $\mathrm{C}_{\mathrm{s}}^{-}$ ${ }^{1}$ values of these monolayers. This trend indicated that increasing levels of Lys-DOPG decreased the area per lipid molecule in these monolayers and hence promoted increasingly denser lipid packing. Similar trends were observed for corresponding monolayers in the presence of MH5 except that higher $\mathrm{C}_{s}^{-1}$ values were generated, indicating that the presence of the peptide promoted relatively denser lipid packing as compared to that in the absence of MH5 (Table 2). For a given level of $\mathrm{X}$, it was found that decreasing $\mathrm{pH}$ also led to increases in the $\mathrm{C}_{\mathrm{s}}^{-1}$ values of monolayers and hence relatively denser lipid packing. For corresponding monolayers in the presence of MH5, similar trends were observed, except that higher $\mathrm{C}_{s}^{-1}$ values were generated, indicating that the presence of the peptide led to relatively denser lipid packing as compared to that in the absence of MH5 (Table 2). In relation to physiological levels of Lys-PG in membranes of $S$. aureus, in the absence of MH5, the $\mathrm{Cs}^{-1}$ of monolayers were $36.1 \mathrm{mN} \mathrm{m}^{-1}(\mathrm{X}=40)$ at $\mathrm{pH} 7$ and $42.9 \mathrm{mN} \mathrm{m}^{-1}(\mathrm{X}$ $=60)$ at $\mathrm{pH}$ 6, indicating that the latter monolayers were more rigid and possessed relatively denser lipid packing than the former (Table 2). The presence of MH5 led to increases in the $\mathrm{C}_{s}^{-1}$ of both these monolayers, which were $43.54 \mathrm{mN} \mathrm{m}^{-1}(\mathrm{X}=40)$ at $\mathrm{pH} 7$ and 109.9 at $\mathrm{mN} \mathrm{m}^{-1}(\mathrm{X}=60)$. 
These latter results indicate that the presence of MH5 increased the rigidity and lipid packing density of both monolayers, which is consistent with the peptide partitioning into these membranes. Moreover, this effect was of the order of ten-fold greater at $\mathrm{pH} 6$ (change in $\mathrm{Cs}^{-1}$ of 63.0) as compared to $\mathrm{pH} 7$ (change in $\mathrm{Cs}_{\mathrm{s}}^{-1}$ of 7.5), indicating that the ability of MH5 to partition into membranes of S. aureus is strongly enhanced by low pH conditions (Table 2).

The compression isotherms of Figure 6 were also used to derive values for the Gibbs free energy of mixing, $\Delta \mathrm{G}_{\mathrm{mix}}$, at $20 \mathrm{mN} \mathrm{m}^{-1}$ for monolayers formed from DOPG:CL:Lys-DOPG in the molar ratio 55:5:X where $\mathrm{X}=0,20,40,60$ or 80 at pH 6, pH 7 and $\mathrm{pH} 8$ (Figure 7). A pH dependent threshold level of Lys-DOPG was observed at which these monolayers become thermodynamically stable, rising from $\mathrm{X}=0$ at $\mathrm{pH} 7$ to $\mathrm{X}=20$ at $\mathrm{pH} 8$ (Figure 7). At each $\mathrm{pH}$ studied, in the absence of MH5, increasing $\mathrm{X}$ led to elevations in the $\Delta \mathrm{G}_{\text {mix }}$ values of these monolayers. This trend indicated that as levels of Lys-DOPG were increased, the thermodynamic stability of these monolayers became progressively higher. Similar trends were observed for corresponding monolayers in the presence of MH5 except that higher $\Delta \mathrm{G}_{\text {mix }}$ values were generated, indicating that the presence of the peptide promoted relatively higher levels of thermodynamic stability in these monolayers, as compared to those formed in the absence of MH5 (Figure 7). For a given level of $\mathrm{X}$, it was found that decreasing $\mathrm{pH}$ also led to increases in the $\Delta \mathrm{G}_{\text {mix }}$ values of monolayers and hence relatively higher levels of thermodynamic stability. For corresponding monolayers in the presence of MH5, similar trends were observed except that higher $\Delta \mathrm{G}_{\text {mix }}$ values were generated, indicating that the presence of the peptide promoted relatively higher levels of thermodynamic stability in these monolayers when compared to those formed in the absence of MH5 (Figure 7). In relation to physiological levels of Lys-DOPG in membranes of S. aureus, in the absence of MH5, the $\Delta \mathrm{G}_{\text {mix }}$ of monolayers were $-2.0(\mathrm{X}=40)$ at $\mathrm{pH} 7$ and $-5.0(\mathrm{X}=60)$ at $\mathrm{pH}$ 
6, indicating that the latter monolayers were thermodynamically more stable than the former monolayers (Figure 7). The presence of MH5 led to increases in the $\Delta \mathrm{G}_{\text {mix }}$ values of both these monolayers, which were $-3.0(\mathrm{X}=40)$ at $\mathrm{pH} 7$ and $-8.0(\mathrm{X}=60)$. These latter results indicate that the presence of MH5 increased the thermodynamic stability of both monolayers and that this effect was in the order of three-times greater at $\mathrm{pH} 6$ (change in $\Delta \mathrm{G}_{\mathrm{mix}}$ of -1) when compared to $\mathrm{pH} 7$ (change in $\Delta \mathrm{G}_{\mathrm{mix}}$ of -3). These results show that the ability of MH5 to increase the thermodynamic stability of membranes of S. aureus is strongly enhanced by low $\mathrm{pH}$ conditions (Figure 7).

The ability of MH5 to permeabilise lipid mimics of S. aureus membranes - Calcein entrapped in vesicles, which were constructed from either, lipid extracts of $S$. aureus membranes, or DOPG:CL:Lys-DOPG in the molar ratio 55:5:X where $X=0,20,40,60$ and 80 or 100, were used to investigate the lytic ability of $\mathrm{MH} 5$ at $\mathrm{pH}$ 6, $\mathrm{pH} 7$ and $\mathrm{pH}$ 8. In the case of vesicles formed from lipid extracts of $S$. aureus membranes, it was found that at each $\mathrm{pH}$ studied, the peptide induced the release of calcein from these vesicles with the level of the dye released increasing as the concentration of MH5 became progressively higher, showing that MH5 was generally lytic to these membranes. At MH5 concentrations of circa $500 \mu \mathrm{M}$, the release of calcein from these vesicles became independent of peptide concentration, indicating that membranes were saturated with MH5 and levels of dye release were maximal, ranging from $40.3 \%$ at $\mathrm{pH} 8$ to $72.6 \%$ at $\mathrm{pH} 6$ (Figure 8). It was also found that the levels of lysis induced by the peptide were enhanced by decreasing $\mathrm{pH}$, for example, at the MIC of MH5 for S. aureus (90 $\mu \mathrm{M})$, levels of dye release induced by the peptide were circa $30 \%$ at pH 8 but rose to $57 \%$ at pH 6 (Figure 8). 
To gain further insight into the membranolytic ability of MH5, vesicles were constructed from DOPG:CL:Lys-DOPG, and it was found that at each pH studied, the peptide induced the release of calcein from these vesicles for all values of X (Figure 9). In the case of both Figure 8 and Figure 9, calcein release from vesicles by MH5 showed kinetics that were similar to the MichaelisMenten-type kinetics of lytic AMPs that utilise 'Carpet'-like mechanisms in their antimicrobial action ${ }^{74,76,80}$. For membranes formed from DOPG:CL:Lys-DOPG, the kinetics of MH5 lytic action were characterized by $\mathrm{K}_{\mathrm{m}}$ values, which provides an inverse measure of the lipid affinity of the peptide and ranged from 38 to $60 \mu \mathrm{M}$ at pH 6, 42 to $65 \mu \mathrm{M}$ at $\mathrm{pH} 7$ and 45 to $68 \mu \mathrm{M}$ at $\mathrm{pH} 8$. These kinetics were also characterized by $E_{\max }$ values, which represent the lytic efficiency of MH5 and varied between 58 and $73 \%$ lysis at pH 6; 45 and $62 \%$ lysis at pH 7; and 40 and $58 \%$ lysis at pH 8 (Figure 9). For the data in Figure 9, a comparison between pH 6 (Figure 6A) and pH 8 (Figure 6C) showed that there was a significant difference between $K_{m}$ values $(p=0.033)$ and $E_{\max }$ values $(p=0.002)$. These data showed that maximal levels of lysis and the lipid affinity of the peptide for a given Lys-DOPG concentration were highest at pH 6 and generally decreased with increasing $\mathrm{pH}$. For example, at $\mathrm{X}=20$ and an MH5 concentration of $250 \mu \mathrm{M}$, the maximal levels of calcein released by the peptide, $\mathrm{E}_{\max }$, increased from $58.0 \%$ at $\mathrm{pH} 8$ to $73.0 \%$ at pH 6 (Figures 9A, and 9C). For the same lytic curve, $\mathrm{K}_{\mathrm{m}}$ decreased from $45 \mu \mathrm{M}$ at $\mathrm{pH} 8$ to $38 \mu \mathrm{M}$ at $\mathrm{pH}$, indicating an increase in the lipid affinity of the peptide (Figures 9A and 9C). The data in Figure 9 also showed that at each $\mathrm{pH}$ studied, for a given peptide concentration, the levels of calcein release induced by MH5 varied inversely with X. This inverse correlation shows clearly that the presence of Lys-DOPG in lipid mimics of $S$. aureus membranes is able to inhibit the ability of MH5 to induce the lysis of these membranes (Figure 9). To investigate the membranolytic ability of MH5 under biologically relevant conditions, Figures 9A, 9B and 9C were used to generate 
Figure 9D. This figure shows the \% lysis induced by MH5 at its MIC of $90 \mu \mathrm{M}$ in vesicles formed DOPG:CL:Lys-DOPG in the molar ratio 55:5:X with varying $\mathrm{X}$ at $\mathrm{pH} 6$ (black crosses), $\mathrm{pH} 7$ (dark grey crosses) and pH 8 (light grey crosses). At the physiological levels of Lys-PG found in membranes of $S$. aureus, this concentration of MH5 induced levels of lysis of circa $40 \%(X=40)$ at $\mathrm{pH} 7$, which rose to $48 \%(\mathrm{X}=60)$ at $\mathrm{pH} 6$, indicating that the ability of the peptide to lyse membranes of the organism is strongly enhanced by the low $\mathrm{pH}$ conditions that are optimal for its growth (Figure 9D).

The haemolytic properties of MH5 - The peptide was assayed for activity against ovine erythrocytes at pH 6, pH 7 and pH 8 (Figure 10). In each case, the peptide showed similar kinetics with haemolysis increasing up to MH5 concentrations of circa $1000 \mu \mathrm{M}$ and then becoming independent of peptide concentration. Levels of haemolysis were generally very low (>2\%) and increased with decreasing $\mathrm{pH}$, for example, at the MIC of MH5 (90 $\mu \mathrm{M})$, the \% haemolysis induced by the peptide varied between $1.6 \%$ at pH 6 and $1.2 \%$ at pH 8 (Figure 10). These levels of haemolysis are comparable to those recently reported for other anionic amphibian AMPs ${ }^{81}$.

\section{DISCUSSION}

The ability of $S$. aureus to proliferate under acidic conditions enables the organism to colonize human epidermal surfaces such as the skin and the anterior nares of the nasal cavity ${ }^{82,83}$. Strains of the organism, including those with methicillin resistance, are responsible for the vast majority of bacterial skin infections in humans ${ }^{84,85}$ and have developed multiple mechanisms to evade antibiotics ${ }^{86,87}$, the adaptive immune response and the action of endogenous AMPs ${ }^{43}, 88$. Currently, therefore, there is a clear need for new drugs with novel mechanisms of action against 
strains of S. aureus ${ }^{89}$ and based on its apparent specificity for the organism ${ }^{7,9}$, here, we have investigated the potential of MH5 to meet this need.

Bacterial membranes are complex and dynamic structures and it is generally accepted that lipid monolayer and vesicle systems provide good mimics of these membranes under in vivo conditions. These lipid systems have the advantage that they adequately reflect the structural characteristics of the membranes they mimic whilst possessing sufficient simplicity to permit systematic analysis of changes in their properties in response to interaction with AMPs ${ }^{18-23,90,91}$. Using these model membrane systems, our data would suggest that the protective effects afforded $S$. aureus against cationic AMPs by the physiological levels of Lys-PG found in membranes of the organism are enhanced by low $\mathrm{pH}$, as recently reported for other bacteria ${ }^{92}$. Here, under acid conditions, the physiological levels of Lys-PG found in membranes of S. aureus (60 \%) promoted a ten-fold increase in the lipid packing density and a three-fold increase in the thermodynamic stability of lipid mimics of these membranes as compared to lipid mimics containing the levels of LyslyPG present in membranes of the organism at pH 7 (40 \%) (Table 2, Figure 7). It has recently been shown that increasing levels of Lys-PG and other lysylated phospholipids promote the rigidification and stabilisation of bacterial membranes through the reduction of electrostatic repulsion between anionic lipid head-groups, thereby inhibiting the ability of AMPs to penetrate these membranes ${ }^{35,36}$. Moreover, it is generally accepted that a contribution to the protective mechanism provided by Lys-PG derives from a 'charge effect' whereby the positively charged head-group carried by the lipid is able to reduce the net negative charge of host bacterial membranes thus inhibiting the binding of cationic AMPs to these membranes $27,28,31,33-38$. It therefore seems likely that the contribution made by 'charge effects' to this protective mechanism is further enhanced by low $\mathrm{pH}$ given that the Lys-PG head-group is predominantly cationic under 
acid conditions but becomes more zwitterionic in character as $\mathrm{pH}$ is increased ${ }^{29,93}$. Taken in combination, these data clearly suggest that the ability of Lys-PG to attenuate the surface charge and lipid packing properties of S. aureus membranes provides the organism with resistance to the action of MH5, which is enhanced under the low $\mathrm{pH}$ conditions that are optimal for the growth of the organism.

A fundamental requirement in the antimicrobial action of AMPs is the ability to accommodate both the polar and apolar compartments of target microbial cells ${ }^{14,94-97}$. Consistent with this ability, MH5 was predicted to adopt amphiphilic $\alpha$-helical structure in an anisotropic environment (Figure 1) and has the potential to form a tilted structure as seen for other membrane interactive $\alpha$ helices ${ }^{98}$. Supporting this prediction, the peptide appeared to adopt such secondary structure at an aqueous interface across the $\mathrm{pH}$ range, $\mathrm{pH} 6$ to $\mathrm{pH}$, and exhibit high levels of surface activity (Figure 2A). Across the same $\mathrm{pH}$ range, MH5 also showed a strong ability to adopt amphiphilic $\alpha$-helical structure in the presence of model S. aureus membranes (Figures 3 and 4) and to partition into these membranes (Figure 5). These observations suggest quite clearly that the activity of MH5 against $S$. aureus may involve membranolytic action, which is the predominant antimicrobial mechanism employed by AMPs ${ }^{14,96}$. Confirming this suggestion, the peptide exhibited $\mathrm{pH}$ dependent lytic action against model $S$. aureus membranes that appeared to be contingent upon the properties of both the peptide itself and these target membranes (Figures 8 and 9). In relation to MH5, the highest levels of this membranolytic activity were observed at low pH (circa $80 \%$ to $90 \%$, Figure 9A; Figures 9B and 9C) when the levels of amphiphilic $\alpha$-helical structure adopted by the peptide were also at their highest (circa $50 \%$ to $60 \%$, Table 1; Figures 3 and 4). This conformational behaviour would maximise the area of the hydrophilic and hydrophobic sites on the surface of MH5 and thereby its ability to penetrate and perturb S. aureus membranes. It is well 
established that similar structural arrangements play a key role in facilitating the bacteriolytic action of many other $\alpha$-helical AMPs ${ }^{14}$. In combination, these observations strongly suggest that the low $\mathrm{pH}$ mediated stabilisation of amphiphilic $\alpha$-helical structure plays a major role in the membranolytic activity of MH5 towards S. aureus.

S. aureus appears to have a number of mechanisms that protect it from the action of cationic AMPs that involve reduction in the negative surface charge of its membrane and outer layers ${ }^{99}$, 100. For example, a recent study suggested that low $\mathrm{pH}$ mediated a decrease in the anionicity of teichoic acids in the organism's peptidoglycan layer, thereby inhibiting the activity of a number of positively charged AMPs ${ }^{101}$. It may therefore be predicted that such protective mechanisms may have a contrary effect in the case of anionic AMPs and enhance the ability of these peptides to target and kill S. aureus. However, our data showed that the membranolytic action of MH5 varied inversely with the Lys-PG content of $S$. aureus membranes at any given $\mathrm{pH}$ in the range, $\mathrm{pH} 6$ to $\mathrm{pH}$ 8, suggesting that Lys-PG has provided a protective effect (Figure 5B). This effect is the opposite to what might be expected for MH5, which is overall anionic, given the ability of LysPG to protect $S$. aureus from the action of cationic AMPs. In combination, these observations may imply that the membranolytic form of MH5 effectively acts as a cationic AMP, which would appear to be the first report of such behaviour for an amphibian peptide although it has been described for anionic AMPs from plants ${ }^{94,95}$. Functioning as a cationic AMP could involve the amidated residues at the termini of the MH5 primary structure, which are positively charged across the $\mathrm{pH}$ range studied here. Moreover, these amidated residues are relatively more accessible to external molecules than the anionic residues possessed by the peptide, which are more centrally located in relation to the longitudinal axis of $\alpha$-helical MH5 ${ }^{11,12,102}$. It also seems likely that the amide moiety at the C-terminus of MH5 helps promote stabilisation of the peptide's $\alpha$-helical 
secondary structure. It is well established that C-terminal amidation provides an extra hydrogen bonding capability that stabilizes amphiphilic $\alpha$-helix formation by AMPs upon membrane binding, thereby enhancing their membranolytic action and antimicrobial activity ${ }^{103,104}$. Together, these observations could help explain why MH5 appears able to evade some adaptive mechanisms of resistance possessed by S. aureus to combat anionic AMPs and how the peptide targets membranes of the organism ${ }^{33,105}$. Indeed, it may also be that the stabilisation of MH5 $\alpha$-helical structure by low $\mathrm{pH}$ optimises the orientation of these amide groups for targeting and binding $S$. aureus membranes, thereby promoting maximal membranolytic activity of the peptide against this organism under $\mathrm{pH}$ conditions optimal for its growth.

Conditions of $\mathrm{pH}$ play a variable role in the interactions of AMPs and microbes. One the one hand, it can play a role in the protection of these organisms by contributing to the proton motive force (PMF) of the CM ${ }^{106}$ and thereby power efflux pumps that extrude AMPs ${ }^{107}$. Low $\mathrm{pH}$ can exert a protective effect by promoting the membrane anchoring of cell wall enzymes and thereby shield these organisms from AMPs ${ }^{108,109}$. Acid conditions have also been shown to promote resistance to AMPs in soil bacteria ${ }^{92}$ and to inhibit the antibacterial activity of endogenous human peptides, such as defensins and LL-37, to organisms found in lungs ${ }^{110,111}$. On the other hand, PMF dependent efflux pumps also appear able to import porcine, bovine and other AMPs, thereby promoting their activity ${ }^{112-114}$. The promotion of antimicrobial action by low $\mathrm{pH}$ has been reported for a number of AMPs, including human hepcidins ${ }^{115}$, gads ${ }^{116}$ clavanins and styelins ${ }^{117}$ from marine organisms, and a range of synthetic peptides ${ }^{118-121}$, along with the anticancer activity of a variety of AMPs ${ }^{16}$. For the most, part, these studies have focussed on cationic AMPs and there has been less research into the effects of $\mathrm{pH}$ on anionic AMPs ${ }^{94,95}$. It has been reported that acid condition promote amyloid formation by dermaseptin PD-3-7, which was predicted to be a AMPs 
storage strategy by the host amphibian ${ }^{122}$ and the membrane interactions of the dermcidin derivative, DCD-1, which is an $\alpha$-helical AMP with potent antibacterial activity ${ }^{123}$. In the present study, MH5 was found to possess levels of circa $45 \%$-helicity at pH 7, which increased to 50 $\% \alpha$-helicity at $\mathrm{pH} 6$ in the presence of lipid mimics of $S$. aureus membranes containing physiological levels of Lys-PG (Figure 4B). MH5 also partitioned into these lipid mimics in a manner that was enhanced by low $\mathrm{pH}$, inducing surface pressure changes of $5.6 \mathrm{mN} \mathrm{m}^{-1}$ at $\mathrm{pH}$, which increased to $6.2 \mathrm{mN} \mathrm{m}^{-1}$ at $\mathrm{pH} 6$ (Figure 5B). These results clearly suggest that the stabilization of $\alpha$-helical structure is a major driver in the ability of MH5 to insert into S. aureus membranes under the low $\mathrm{pH}$ conditions that are optimal for the growth of the organism. Moreover, surface pressure changes of this order suggest that MH5 inserts primarily into the lipid head-group region of these membranes, as reported for other cationic AMPs ${ }^{104}$. The presence of MH5 led to increases in the lipid packing density of these membrane mimics, which were ten-fold greater at $\mathrm{pH} 6$ as compared to the corresponding effects at $\mathrm{pH}$ 7, which is consistent with the enhanced ability of the peptide to partition into these membranes at low $\mathrm{pH}$ (Table 2). The presence of MH5 also led to increases in thermodynamic stability of these membrane mimics, which were three-fold greater at $\mathrm{pH} 6$ as compared to the corresponding effects at $\mathrm{pH} 7$ (Figure 7). In combination, these results suggest that acid conditions facilitated the ability of MH5 to partition into membranes of $S$. aureus via surface associated binding of the peptide that permits the bridging of anionic lipid head-groups, thereby stabilizing the structure of the membrane, as recently reported for other cationic peptides with activity against the organism ${ }^{23}$ and for other tilted peptides involved in membrane binding ${ }^{98}$. Most probably, this bridging function is served by the two terminal amide groups possessed by MH5 given that these are they are only positively charged residues possessed by the peptide and, as suggested above, low $\mathrm{pH}$ appears to stabilize MH5 $\alpha$ - 
helical structure thereby optimising the orientation of these amide groups for binding $S$. aureus membranes. Indeed, given that the anionic residues possessed by the peptide form a centrally located cluster in relation to the longitudinal axis of $\alpha$-helical MH5 (Figure 1C), we speculate that these residues may complement the bridging function of the peptide by interacting with the headgroups of Lys-PG.

Although it is generally accepted that lipid vesicle systems provide good mimics of bacterial membranes, the permeabilization of these systems by AMPs shows complex behaviour ${ }^{90,91}$ and work on these peptides therefore tends to compare the relative profiles of lysis between AMPs rather than with other pharmacological processes ${ }^{80,124}$. Using this approach appeared to show that MH5 possessed a strong ability to permeabilise lipid mimics of S. aureus membranes containing physiologically relevant levels of Lys-PG, which at the MIC of the peptide (90 $\mu \mathrm{M})$, were circa $40 \%$ lysis at $\mathrm{pH} 7$, increasing to around $48 \%$ lysis at $\mathrm{pH} 6$ (Figure 9D). There is the possibility that this $\mathrm{pH}$ dependent release of calcein from vesicles was related to the physical properties of these lipid bodies. For example, heterogeneity in their ability to function as lipid permeability barriers may facilitate higher levels of dye release at lower $\mathrm{pH}$ or some entrapped calcein could be bound to lipid and only released by vesicles at lower $\mathrm{pH}$. However, correlating with our calcein release data (Figure 9), low pH strongly enhanced the ability of MH5 to both adopt membrane interactive structure (Figure 4) and penetrate monolayers with the same lipid compositions as our vesicle systems (Figure 5). Taken in combination, these results strongly suggest that MH5 has an ability to lyse membranes of $S$. aureus that has a low $\mathrm{pH}$ optimum, thereby facilitating killing of the organism under the biologically relevant $\mathrm{pH}$ conditions that are optimal for its growth. Based on our data, it is difficult to provide a clear picture of the bacteriolytic mechanism used by MH5 but the acid facilitated ability of the peptide to stabilise membranes of $S$. aureus (Table 2, Figure 
7) via head-group partitioning (Figure 5) prior to lytic action (Figure 9) is suggestive of a 'Carpet'like mechanism of membranolysis. Using this mechanism, AMPs 'carpet' the target membrane surface in a nonspecific manner until a critical peptide concentration is reached when the induction of lesions leads to the disruption of lipid packing and bilayer disintegration ${ }^{14,125}$. Indeed, this suggestion is further supported by the observation that the lytic action of MH5 (Figures 8 and 9) generally showed kinetics that were similar to the Michaelis-Menten-type kinetics of lytic AMPs that utilise 'Carpet'-like mechanisms in their antimicrobial action, typically the amphibian peptide, aurein $2.5^{74,76,80}$. Based on this similarity in kinetics, we speculate that increasing concentrations of MH5 in our membrane systems led to progressively greater numbers of lesions in these membranes with the additive effect of these lesions resulting in the maximal levels of membranolysis observed for the peptide (Figure 9). The kinetics of the lysis curves representing this membranolytic action were differentiated by their characteristic $\mathrm{K}_{\mathrm{m}}$ values, which provides an inverse measure of the affinity of MH5 for our membrane systems and ranged between $38 \mu \mathrm{M}$ at pH 6 to $68 \mu \mathrm{M}$ at pH 8 (Figure 9). As shown for other AMPs that use the Carpet mechanism, these differing lipid affinities would affect the properties of the membrane lesions induced by the peptide, such as depth, size and temporal stability ${ }^{14,126}$. Differences in the properties of these lesions would then lead to the differing lytic efficiencies and varying levels of maximal membranolysis shown by the peptide for our membrane systems, indicated by their $\mathrm{E}_{\max }$ values, which ranged between $40 \%$ at pH 8 and $73 \%$ at pH $6 \%$ (Figure 9). These data clearly suggest that acid conditions promote the ability of MH5 to kill S. aureus by enhancing the lipid affinity of the peptide and thereby its capacity for membranolyic action. Moreover, these data also indicate that the lipid affinity of MH5 is much lower than that of cationic AMPs ${ }^{124}$ and could help explain the relatively high MIC of the peptide $(90 \mu \mathrm{M})$. It is generally accepted that anionic AMPs have 
less potent antimicrobial activity than their cationic counterparts and it has been suggested that the former peptides arose to complement the action of the latter peptides, in combating microbial resistance mechanisms for example ${ }^{94}$. It is interesting to note that a number of amphibian AMPs appear to kill bacteria via the 'Carpet' mechanism ${ }^{127-130}$ with tilted structure incorporated into their lytic action ${ }^{68,73,131}$ and the partitioning of peptides via the use of tilted $\alpha$-helices to anchor to the membrane has been observed ${ }^{98}$. MH5 showed the potential to form a tilted $\alpha$-helix (Figure 1) with compositional and structural similarities to that formed by the HA2 peptide (Figure 1A and 1B), which is also anionic and exhibits enhanced levels of $\alpha$-helicity and membrane perturbation at low $\mathrm{pH}^{68-70}$. It may therefore be that the low $\mathrm{pH}$ mediated stabilisation of MH5 tilted structure promotes the membranolytic activity of the peptide towards $S$. aureus, which would constitute a $\mathrm{pH}$ dependent mechanism of antimicrobial action that does not yet appear to have been described for AMPs.

In summary, our data clearly show that $S$. aureus has developed Lys-PG mediated mechanisms of resistance to AMPs that give the organism some protection from the action of maximin H5. The peptide is able to overcome these resistance mechanisms, although its MIC is relatively high for AMPs, which may reflect the effect of these protective mechanisms. The action of maximin H5 against $S$. aureus involves a membranolytic mode of action that is facilitated by the adoption of amphiphilic $\alpha$-helical structure by the peptide and is enhanced by $\mathrm{pH}$ conditions that favour the growth of the organism. Indeed, it is tempting to speculate that the secretion of MH5 by the host toad, B. maxima ${ }^{7}$, may have developed specifically to combat the organism, particularly in view of the fact that $S$. aureus appears to be the sole bacterial target of the peptide ${ }^{7,9}$. Taking these observations with the generally low levels and manipulability of maximin H5's haemolytic activity (Figure 10) 7,8,102, it would seem that the peptide is worthy of further investigation as a 
potential template for development as an anti-staphylococcal agent in areas under investigation for other AMPs such as surface decontaminants ${ }^{132}$, topical anti-infectives ${ }^{133}$ and animal husbandry agents ${ }^{134}$. Indeed, although maximin H5 has no antiviral properties itself, the peptide seems to constitute a highly malleable template for the production of derivatives with activity against these organisms. Strongly basic derivatives of maximin H5 were found to have potent activity against the human immune-deficiency virus ${ }^{9}$ whilst isoforms of the peptide with no net charge were found to be strongly antiviral when coupled to activated fullerenes, which acted as a novel nanocarrier 135. Taken with the rapid progress in addressing problems associated with the therapeutic development of AMPs, such as proteolytic stability and systemic toxicity ${ }^{103}$, it may be that the template provided by maximin $\mathrm{H} 5$ is able to expand the range of amphibian peptides that are already in clinical trials 133, 136, 137 . 


\section{REFERENCES}

[1] König, E., Bininda-Emonds, O. R. P., and Shaw, C. (2015) The diversity and evolution of anuran skin peptides, Peptides 63, 96-117.

[2] Xiao, Y., Liu, C., and Lai, R. (2011) Antimicrobial peptides from amphibians, Biomol Concepts 2, 27-38.

[3] Oelkrug, C., Hartke, M., and Schubert, A. (2015) Mode of Action of Anticancer Peptides (ACPs) from Amphibian Origin, Anticancer Res. 35, 635-643.

[4] Conlon, J. M., Mechkarska, M., Lukic, M. L., and Flatt, P. R. (2014) Potential therapeutic applications of multifunctional host-defense peptides from frog skin as anti-cancer, antiviral, immunomodulatory, and anti-diabetic agents, Peptides 57, 67-77.

[5] Conlon, J. M., and Sonnevend, S. (2011) Clinical Applications of Amphibian Antimicrobial Peptides, J. Med. Sci. 4, 62-72.

[6] Silva, R. R., Avelino, K., Ribeiro, K. L., Franco, O. L., Oliveira, M. D. L., and Andrade, C. A. S. (2014) Optical and dielectric sensors based on an microbial peptides for microorganism diagnosis, Front. Microbiol. 5, 443. http://doi.org/10.3389/fmicb.2014.00443

[7] Lai, R., Liu, H., Hui Lee, W., and Zhang, Y. (2002) An anionic antimicrobial peptide from toad Bombina maxima, Biochem; Biophys. Res. Commun. 295, 796-799.

[8] Liu, R., Liu, H., Ma, Y., Wu, J., Yang, H., Ye, H., and Lai, R. (2011) There are Abundant Antimicrobial Peptides in Brains of Two Kinds of Bombina Toads, J. Proteome Res. 10, 1806-1815.

[9] Wang, G., Watson, K. M., Peterkofsky, A., and Buckheit, R. W., Jr. (2010) Identification of Novel Human Immunodeficiency Virus Type 1-Inhibitory Peptides Based on the Antimicrobial Peptide Database, Antimicro.b Agents Chemother. 54, 1343-1346.

[10] Phoenix, D. A., Dennison, S. R., and Harris, F. (2013) Graphical Techniques to Visualize the Amphiphilic Structures of Antimicrobial Peptides, In Antimicrobial Peptides, pp 115-144, Wiley-VCH Verlag GmbH \& Co. KGaA.

[11] Dennison, S. R., Harris, F., Mura, M., Morton, L. H. G., Zvelindovsky, A., and Phoenix, D. A. (2013) A Novel Form of Bacterial Resistance to the Action of Eukaryotic Host Defense Peptides, the Use of a Lipid Receptor, Biochemistry 52, 6021-6029.

[12] Phoenix, D. A., Harris, F., Mura, M., and Dennison, S. R. (2015) The increasing role of phosphatidylethanolamine as a lipid receptor in the action of host defence peptides, Prog. Lipid Res. 59, 26-37.

[13] Teixeira, V., Feio, M. J., and Bastos, M. (2012) Role of lipids in the interaction of antimicrobial peptides with membranes, Prog. Lipid Res. 51, 149-177.

[14] Phoenix, D. A., Dennison, S. R., and Harris, F. (2013) Models for the Membrane Interactions of Antimicrobial Peptides, In Antimicrobial Peptides, pp 145-180, Wiley-VCH Verlag GmbH \& Co. KGaA.

[15] Epand, R. M., and Epand, R. F. (2011) Bacterial membrane lipids in the action of antimicrobial agents, J. Pept. Sci. 17, 298-305.

[16] Harris, F., Dennison, S. R., Singh, J., and Phoenix, D. A. (2013) On the selectivity and efficacy of defense peptides with respect to cancer cells, Med. Res. Rev. 33, 190-234.

[17] Wilmes, M., Cammue, B. P. A., Sahl, H.-G., and Thevissen, K. (2011) Antibiotic activities of host defense peptides: more to it than lipid bilayer perturbation, Nat Prod Rep. 28, 13501358. 
[18] Dennison, S. R., Harris, F., and Phoenix, D. A. (2010) A Langmuir Approach Using Monolayer Interactions to Investigate Surface Active Peptides, Protein Pept. Lett. 17, 1363-1375.

[19] Wiese, A., Gutsmann, T., and Seydel, U. (2003) Towards antibacterial strategies: studies on the mechanisms of interaction between antibacterial peptides and model membranes, $J$. Endotoxin Res. 9, 67-84.

[20] Chan, Y.-H. M., and Boxer, S. G. (2007) Model membrane systems and their applications, Curr. Opin. Chem. Biol. 11, 581-587.

[21] Peetla, C., Stine, A., and Labhasetwar, V. (2009) Biophysical interactions with model lipid membranes: applications in drug discovery and drug delivery, Mol. Pharm. 6, 1264-1276.

[22] Dennison, S. R., Harris, F., and Phoenix, D. A. (2014) Chapter Three - Langmuir-Blodgett Approach to Investigate Antimicrobial Peptide-Membrane Interactions, In Advances in Planar Lipid Bilayers and Liposomes (Aleš, I., and Chandrashekhar, V. K., Eds.), pp 83110, Academic Press.

[23] Andra, J., Goldmann, T., Ernst, C. M., Peschel, A., and Gutsmann, T. (2011) Multiple peptide resistance factor (MprF)-mediated Resistance of Staphylococcus aureus against antimicrobial peptides coincides with a modulated peptide interaction with artificial membranes comprising lysyl-phosphatidylglycerol, J. Biol. Chem. 286, 18692-18700.

[24] van Meer, G., Voelker, D. R., and Feigenson, G. W. (2008) Membrane lipids: where they are and how they behave, Nat. Rev. Mol. Cell Biol 9, 112-124.

[25] Wang, G., Li, X., and Wang, Z. (2009) APD2: the updated antimicrobial peptide database and its application in peptide design, Nucleic Acids Res. 37, D933-D937.

[26] Wang, G., Li, X., and Zasloff, M. (2010) A Database View of Naturally Occurring Antimicrobial Peptides: Nomenclature, Classification and Amino Acid Sequence Analysis. In Antimicrobial peptides: discovery, design and novel therapeutic strategies (Wang, G., Li, X., and Zasloff, M.. Ed) pp 1-21, CABI.

[27] Roy, H. (2009) Tuning the properties of the bacterial membrane with aminoacylated phosphatidylglycerol, IUBMB Life 61, 940-953.

[28] Goldfine, H. (2014) Charge counter charge Bacterial response to antimicrobial cationic peptides and more, Virulence 5, 451-453.

[29] Rehal, R. P. (2013) A Physicochemical and Biophysical Investigation into the Role of LysylPhosphatidylglycerol in the Membrane of Staphylococcus aureus under mild acidic conditions, In School of Biomedical and Health Sciences of King's College London, p 267, King's College, London.

[30] Rode, T. M., Møretrø, T., Langsrud, S., and Holck, A. (2012) Responses of Staphylococcus aureus to Environmental Stresses, In Stress Response of Foodborne Microorganisms (Wong, H., Ed.), pp 509-546, Nova Science Publishers.

[31] Yang, S.-J., Bayer, A. S., Mishra, N. N., Meehl, M., Ledala, N., Yeaman, M. R., Xiong, Y. Q., and Cheung, A. L. (2012) The Staphylococcus aureus Two-Component Regulatory System, GraRS, Senses and Confers Resistance to Selected Cationic Antimicrobial Peptides, Infect. Immun. 80, 74-81.

[32] Falord, M., Mader, U., Hiron, A., Debarbouille, M., and Msadek, T. (2011) Investigation of the Staphylococcus aureus GraSR regulon reveals novel links to virulence, stress response and cell wall signal transduction pathways, PLoS One 6, e21323.

[33] Joo, H.-S., and Otto, M. (2015) Mechanisms of resistance to antimicrobial peptides in staphylococci, Biochim. Biophys. Acta..1748, 3055-3061. 
[34] Staubitz, P., Neumann, H., Schneider, T., Wiedemann, I., and Peschel, A. (2004) MprFmediated biosynthesis of lysylphosphatidylglycerol, an important determinant in staphylococcal defensin resistance, FEMS Microbiol. Lett. 231, 67-71.

[35] Cox, E., Michalak, A., Pagentine, S., Seaton, P., and Pokorny, A. (2014) Lysylated phospholipids stabilize models of bacterial lipid bilayers and protect against antimicrobial peptides, Biochim. Biophys. Acta 1838, 2198-2204.

[36] Kilelee, E., Pokorny, A., Yeaman, M. R., and Bayer, A. S. (2010) Lysyl-phosphatidylglycerol attenuates membrane perturbation rather than surface association of the cationic antimicrobial peptide 6W-RP-1 in a model membrane system: implications for daptomycin resistance, Antimicrob. Agents Chemother. 54, 4476-4479.

[37] Danner, S., Pabst, G., Lohner, K., and Hickel, A. (2008) Structure and thermotropic behavior of the Staphylococcus aureus lipid lysyl-dipalmitoylphosphatidylglycerol, Biophys. J. 94, 2150-2159.

[38] LaRock, C. N., and Nizet, V. (2015) Cationic antimicrobial peptide resistance mechanisms of streptococcal pathogens, Biochim. Biophys. Acta. 148, 3047-3054.

[39] Gould, R. M., and Lennarz, W. J. (1970) Metabolism of Phosphatidylglycerol and Lysyl Phosphatidylglycerol in Staphylococcus aureus, J. Bacteriol. 104, 1135-1144.

[40] Haest, C. W. M., Vandeene.Ll, Degier, J., Bartels, P., and Opdenkam.J. (1972) , Biochim. Biophys. Acta. 255, 720-

[41] Mukhopadhyay, K., Whitmire, W., Xiong, Y. Q., Molden, J., Jones, T., Peschel, A., Staubitz, P., Adler-Moore, J., McNamara, P. J., Proctor, R. A., Yeaman, M. R., and Bayer, A. S. (2007) In vitro susceptibility of Staphylococcus aureus to thrombin-induced platelet microbicidal protein-1 (tPMP-1) is influenced by cell membrane phospholipid composition and asymmetry, Microbiology-(UK) 153, 1187-1197.

[42] Leary, W. M., and G., W. S. (2007) Gram-positive bacteria, In Microbial Lipids (Ratledge, C. a. W., S. G. , Ed.), pp 117-201, Academic Press, London.

[43] Ryu, S., Song, P. I., Seo, C. H., Cheong, H., and Park, Y. (2014) Colonization and Infection of the Skin by S. aureus: Immune System Evasion and the Response to Cationic Antimicrobial Peptides, Int. J. Mol. Sci. 15, 8753-8772.

[44] Heimlich, D., Harrison, A., and Mason, K. (2014) Host Antimicrobial Peptides in Bacterial Homeostasis and Pathogenesis of Disease, Antibiotics 3, 645.

[45] Poole, K. (2012) Bacterial stress responses as determinants of antimicrobial resistance, $J$. Antimicrob. Chemother. 2012. 1-21.

[46] Li, M., Cha, D. J., Lai, Y., Villaruz, A. E., Sturdevant, D. E., and Otto, M. (2007) The antimicrobial peptide-sensing system aps of Staphylococcus aureus, Mol. Microbiol. 66, 1136-1147.

[47] Li, M., Lai, Y., Villaruz, A. E., Cha, D. J., Sturdevant, D. E., and Otto, M. (2007) Grampositive three-component antimicrobial peptide-sensing system, Proc. Natl. Acad. Sci. U S A 104, 9469-9474.

[48] Otto, M. (2009) Bacterial Sensing of Antimicrobial Peptides, In Bacterial Sensing and Signaling (Collin, M., and Schuch, R., Eds.), pp 136-149.

[49] Bligh, E. G., and Dyer, W. J. (1959) A rapid method of total lipid extraction and purification, Can. J. Med. Sci .37, 911-917.

[50] Eisenberg, D., Schwarz, E., Komaromy, M., and Wall, R. (1984) Analysis of membrane and surface protein sequences with the hydrophobic moment plot, J. Mol. Biol. 179, 125-142. 
[51] Eisenberg, D., Weiss, R. M., Terwillinger, T. C., and Wilcox, W. (1982) Hydrophobic moment and protein structure, Farad. Symp. Chem. Soc. 17, 109-120.

[52] Eisenberg, D., Weiss, R. M., and Terwilliger, T. C. (1982) The helical hydrophobic moment: a measure of the amphiphilicity of a helix, Nature 299, 371-374.

[53] Harris, F., Wallace, J., and Phoenix, D. A. (2000) Use of hydrophobic moment plot methodology to aid the identification of oblique orientated alpha-helices, Mol. Membr. Biol. 17, 201-207.

[54] Schiffer, M., and Edmundson, A. B. (1967) Use of helical wheels to represent the structures of proteins and to identify segments with helical potential, Biophys. J. 7, 121-135.

[55] Greenfield, N. J. (2006) Using circular dichroism spectra to estimate protein secondary structure, Nat. Protoc. 6, 2876-2890.

[56] Henzler Wildman, K. A., Lee, D. K., and Ramamoorthy, A. (2003) Mechanism of lipid bilayer disruption by the human antimicrobial peptide, LL-37, Biochemistry 42, 6545-6558.

[57] Whitmore, L., Woollett, B., Miles, A. J., Janes, R. W., and Wallace, B. A. (2010) The protein circular dichroism data bank, a Web-based site for access to circular dichroism spectroscopic data, Structure 18, 1267-1269.

[58] Whitmore, L., and Wallace, B. A. (2008) Protein secondary structure analyses from circular dichroism spectroscopy: methods and reference databases, Biopolymers 89, 392-400.

[59] Whitmore, L., and Wallace, B. A. (2004) DICHROWEB, an online server for protein secondary structure analyses from circular dichroism spectroscopic data, Nucleic Acids Res. 32, W668-673.

[60] Seelig, A. (1987) Local anesthetics and pressure: a comparison of dibucaine binding to lipid monolayers and bilayers, Biochim Biophys. Acta 899, 196-204.

[61] Davies, J. T., and Rideal, E. K. (1963) Properties of monolayers, in Interfacial Phenomena, 2nd ed., pp 265, Academic Press, New York.

[62] Roa, G (2010) Numerical differentiation and integration, in Mathematical Methods. pp 150165, International Publishing House Pvt. Limited, New Delhi.

[63] Dennison, S. R., and Phoenix, D. A. (2014) Susceptibility of sheep, human, and pig erythrocytes to haemolysis by the antimicrobial peptide Modelin 5, Eur. Biophys. J. s 43, 423-432.

[64] Phoenix, D. A., Harris, F., Daman, O. A., and Wallace, J. (2002) The prediction of amphiphilic alpha-helices, Curr. Protein Pept. Sci. 3, 201-221.

[65] Phoenix, D. A., and Harris, F. (2002) The hydrophobic moment and its use in the classification of amphiphilic structures (Review), Mol. Membr. Biol. 19, 1-10.

[66] Dennison, S. R., Morton, L. H. G., Brandenburg, K., Harris, F., and Phoenix, D. A. (2006) Investigations into the ability of an oblique alpha-helical template to provide the basis for design of an antimicrobial anionic amphiphilic peptide, Febs J. 273, 3792-3803.

[67] Harris, F., Daman, A., Wallace, J., Dennison, S. R., and Phoenix, D. A. (2006) Oblique orientated alpha-helices and their prediction, Curr. Protein Pept. Sci. 7, 529-537.

[68] Dennison, S. R., Harris, F., and Phoenix, D. A. (2005) Are oblique orientated alpha-helices used by antimicrobial peptides for membrane invasion?, Prot. Peptid. Letts. 12, 27-29.

[69] Lins, L., Decaffmeyer, M., Thomas, A., and Brasseur, R. (2008) Relationships between the orientation and the structural properties of peptides and their membrane interactions, Biochimica Biophys. Acta 1778, 1537-1544. 
[70] Han, X., Bushweller, J. H., Cafiso, D. S., and Tamm, L. K. (2001) Membrane structure and fusion-triggering conformational change of the fusion domain from influenza hemagglutinin, Nat. Struct. Mol. Biol. 8, 715-720.

[71] Fujii, G. (1999) To fuse or not to fuse: the effects of electrostatic interactions, hydrophobic forces, and structural amphiphilicity on protein-mediated membrane destabilization, $A d v$. Drug Deliv. Rev. 38, 257-277.

[72] Harris, F., Dennison, S., and Phoenix, D. A. (2006) The prediction of hydrophobicity gradients within membrane interactive protein alpha-helices using a novel graphical technique, Prot. Peptid. Letts. 13, 595-600.

[73] Mura, M., Dennison, S. R., Zvelindovsky, A. V., and Phoenix, D. A. (2013) Aurein 2.3 functionality is supported by oblique orientated alpha-helical formation, Biochim. Biophys. Acta 1828, 586-594.

[74] Dennison, S. R., Morton, L. H., and Phoenix, D. A. (2012) Role of molecular architecture on the relative efficacy of aurein 2.5 and modelin 5, Biochim. Biophys. Acta 1818, 2094-2102.

[75] Alminana, N., Alsina, M. A., Ortiz, A., and Reig, F. (2004) Comparative physicochemical study of SIKVAV peptide and its retro and retro-enantio analogues, Colloids Surf A: Physicochem. Eng. Asp. 249, 19-24.

[76] Dennison, S. R., Morton, L. H., Shorrocks, A. J., Harris, F., and Phoenix, D. A. (2009) A study on the interactions of Aurein 2.5 with bacterial membranes, Colloids Surf B Biointerfaces 68, 225-230.

[77] Casas, J., Espina, M., Haro, M., Royo, F., Alsina, M. A., Haro, I., and Mestres, C. (2006) Interfacial properties of a synthetic peptide derived from hepatitis $G$ virus E2 protein: interaction with lipid monolayers, Langmuir 22, 246-254.

[78] Dennison, S. R., Kim, Y. S., Cha, H. J., and Phoenix, D. A. (2008) Investigations into the ability of the peptide, HAL18, to interact with bacterial membranes, Eur. Biophys. J. 38, 37-43.

[79] Vie, V., Van Mau, N., Chaloin, L., Lesniewska, E., Le Grimellec, C., and Heitz, F. (2000) Detection of peptide-lipid interactions in mixed monolayers, using isotherms, atomic force microscopy, and fourier transform infrared analyses, Biophys. J. 78, 846-856.

[80] Dennison, S. R., Harris, F., Morton, L. H. G., and Phoenix, D. A. (2013) Antimicrobial activity of aurein 2.5 against yeasts, FEMS Microbiol. Lett. 346, 140-145.

[81] Wei, L., Che, H., Han, Y., Lv, J., Mu, L., Lv, L., Wu, J., and Yang, H. (2015) The first anionic defensin from amphibians, Amino Acids 47, 1301-1308.

[82] Frank, D. N., Feazel, L. M., Bessesen, M. T., Price, C. S., Janoff, E. N., and Pace, N. R. (2010) The human nasal microbiota and Staphylococcus aureus carriage, PLoS One 5, e10598.

[83] Coates, R., Moran, J., and Horsburgh, M. J. (2014) Staphylococci: colonizers and pathogens of human skin, Future Microbiol. 9, 75-91.

[84] de la Gandara, M. P., Garay, J. A. R., Mwangi, M., Tobin, J. N., Tsang, A., Khalida, C., D'Orazio, B., Kost, R. G., Leinberger-Jabari, A., Coffran, C., Evering, T. H., Coller, B. S., Balachandra, S., Urban, T., Parola, C., Salvato, S., Jenks, N., Wu, D. R., Burgess, R., Chung, M., de Lencastre, H., and Tomasz, A. (2015) Molecular Types of MethicillinResistant Staphylococcus aureus and Methicillin-Sensitive S. aureus Strains Causing Skin and Soft Tissue Infections and Nasal Colonization, Identified in Community Health Centers in New York City, J. Clin. Microbiol. 53, 2648-2658. 
[85] David, M. Z., and Daum, R. S. (2010) Community-Associated Methicillin-Resistant Staphylococcus aureus: Epidemiology and Clinical Consequences of an Emerging Epidemic, Clin. Microbiol. Rev. 23, 616-687.

[86] Hiramatsu, K., Katayama, Y., Matsuo, M., Sasaki, T., Morimoto, Y., Sekiguchi, A., and Baba, T. (2014) Multi-drug-resistant Staphylococcus aureus and future chemotherapy, J. Infect. Chemother. 20, 593-601.

[87] Batabyal, B., Kundu, G. K. R., and Biswas, S. (2012) Methicillin-resistant Staphylococcus aureus: A brief review, Int. J. Biol. Sci. 1, 65-71.

[88] Krishna, S., and Miller, L. (2012) Innate and adaptive immune responses against Staphylococcus aureus skin infections, Semin Immunopathol. 34, 261-280.

[89] World Health Organization. (2014) Antimicrobial resistance: global report on surveillance 2014., Geneva, Switzerland.

[90] Wimley, W. C. (2010) Describing the Mechanism of Antimicrobial Peptide Action with the Interfacial Activity Model, ACS Chem. Biol. 5, 905-917.

[91] Wimley, W. C., and Hristova, K. (2011) Antimicrobial Peptides: successes, challenges and unanswered questions, J. Membr. Biol. 239, 27-34.

[92] Sohlenkamp, C., Galindo-Lagunas, K. A., Guan, Z., Vinuesa, P., Robinson, S., ThomasOates, J., Raetz, C. R. H., and Geiger, O. (2007) The Lipid Lysyl-Phosphatidylglycerol Is Present in Membranes of Rhizobium tropici CIAT899 and Confers Increased Resistance to Polymyxin B Under Acidic Growth Conditions, Mol. Plant Microbe. Interact. 20, 14211430.

[93] Tocanne, J. F., Ververgaert, P. H. J. T., Verkleij, A. J., and van Deenen, L. L. M. (1974) A monolayer and freeze-etching study of charged phospholipids I. Effects of ions and $\mathrm{pH}$ on the ionic properties of phosphatidylglycerol and lysylphosphatidylglycerol, Chem. Phys. Lipids. 12, 201-219.

[94] Harris, F., Dennison, S. R., and Phoenix, D. A. (2009) Anionic Antimicrobial Peptides from Eukaryotic Organisms, Curr. Protein Pept. Sci. 10, 585-606.

[95] Harris, F., Dennison, S. R. and Phoenix, D. A. (2011) Anionic Antimicrobial Peptides from Eukaryotic Organisms and their Mechanisms of Action, Curr. Opin. Chem. Biol. 5, 142153.

[96] Lee, T.-H., Hall, K. N., and Aguilar, M.-I. (2016) Antimicrobial Peptide Structure and Mechanism of Action: A Focus on the Role of Membrane Structure, Curr .Top. Med. Chem. 16, 25-39.

[97] Phoenix, D. A., Dennison, S. R., and Harris, F. (2013) Cationic Antimicrobial Peptides, In Antimicrobial Peptides, pp 39-81, Wiley-VCH Verlag GmbH \& Co. KGaA.

[98] Dennison, S. R., Dante, S., Hauß, T., Brandenburg, K., Harris, F., and Phoenix, D. A. (2005) Investigations into the Membrane Interactions of m-Calpain Domain V, Biophys. J.88, 3008-3017.

[99] Nawrocki, K. L., Crispell, E. K., and McBride, S. M. (2014) Antimicrobial Peptide Resistance Mechanisms of Gram-Positive Bacteria, Antibiotics (Basel, Switzerland) 3, 461-492.

[100] Guilhelmelli, F., Vilela, N., Albuquerque, P., Derengowski, L., Silva-Pereira, I., and Kyaw, C. (2013) Antimicrobial development challenges: the various mechanisms of action of antimicrobial peptides and of bacterial resistance, Front.Microbiol 4. 1-12

[101] Walkenhorst, W. F., Klein, J. W., Vo, P., and Wimley, W. C. (2013) pH Dependence of microbe sterilization by cationic antimicrobial peptides, Antimicrob. Agents Chemother. 57, 3312-3320. 
[102] Dennison, S. R., Mura, M., Harris, F., Morton, L. H. G., Zvelindovsky, A., and Phoenix, D. A. (2015) The role of C-terminal amidation in the membrane interactions of the anionic antimicrobial peptide, maximin H5, Biochim. Biophys Acta 1848, 1111-1118.

[103] Aoki, W., and Ueda, M. (2013) Characterization of Antimicrobial Peptides toward the Development of Novel Antibiotics, Pharmaceuticals 6, 1055-1081.

[104] Dennison, S. R., and Phoenix, D. A. (2011) Influence of C-terminal amidation on the efficacy of modelin-5, Biochemistry 50, 1514-1523.

[105] Lai, Y., Villaruz, A. E., Li, M., Cha, D. J., Sturdevant, D. E., and Otto, M. (2007) The human anionic antimicrobial peptide dermcidin induces proteolytic defence mechanisms in staphylococci, Mol. Microbiol. 63, 497-506.

[106] Krulwich, T. A and Ivey D.M. (1990) Chapter 14 - Bioenergetics in Extreme Environments, in Bacterial Energetics. A Treatise on Structure and Function. pp. 417-447 Academic Press, United Kingdom.

[107] Phoenix, D. A., Dennison, S. R., and Harris, F. (2016) Bacterial resistance to host defence peptides, In Host Defense Peptides and Their Potential as Therapeutic Agents (Epand, R. M., Ed.), p 386, Springer International Publishing.

[108] Siligardi, G., Harris, F., and Phoenix, D. A. (1997) $\alpha$-Helical conformation in the C-terminal anchoring domains of E. coli penicillin-binding proteins 4, 5 and 6, Biochim. Biophys. Acta 1329, 278-284.

[109] Harris, F., Demel, R., de Kruijff, B., and Phoenix, D. A. (1998) An investigation into the lipid interactions of peptides corresponding to the C-terminal anchoring domains of Escherichia coli penicillin-binding proteins 4, 5 and 6, Biochim. Biophys. Acta. 1415, 1022.

[110] Pezzulo, A. A., Tang, X. X., Hoegger, M. J., Abou Alaiwa, M. H., Ramachandran, S., Moninger, T. O., Karp, P. H., Wohlford-Lenane, C. L., Haagsman, H. P., van Eijk, M., Banfi, B., Horswill, A. R., Stoltz, D. A., McCray, P. B., Jr., Welsh, M. J., and Zabner, J. (2012) Reduced airway surface $\mathrm{pH}$ impairs bacterial killing in the porcine cystic fibrosis lung, Nature 487, 109-113

[111] Abou Alaiwa, M. H., Reznikov, L. R., Gansemer, N. D., Sheets, K. A., Horswill, A. R., Stoltz, D. A., Zabner, J., and Welsh, M. J. (2014) pH modulates the activity and synergism of the airway surface liquid antimicrobials beta-defensin-3 and LL-37, Proc. Natl. Acad. Sci. U S A. 111, 18703-18708.

[112] Mattiuzzo, M., Bandiera, A., Gennaro, R., Benincasa, M., Pacor, S., Antcheva, N., and Scocchi, M. (2007) Role of the Escherichia coli SbmA in the antimicrobial activity of proline-rich peptides, Mol. Microbiol. 66, 151-163.

[113] Pranting, M., Negrea, A., Rhen, M., and Andersson, D. I. (2008) Mechanism and fitness costs of PR-39 resistance in Salmonella enterica serovar Typhimurium LT2, Antimicrob. Agents Chemother. 52, 2734-2741.

[114] Warner, D. M., and Levy, S. B. (2010) Different effects of transcriptional regulators MarA, SoxS and Rob on susceptibility of Escherichia coli to cationic antimicrobial peptides (CAMPs): Rob-dependent CAMP induction of the marRAB operon, Microbiology-Sgm 156, 570-578.

[115] Maisetta, G., Vitali, A., Scorciapino, M. A., Rinaldi, A. C., Petruzzelli, R., Brancatisano, F. L., Esin, S., Stringaro, A., Colone, M., Luzi, C., Bozzi, A., Campa, M., and Batoni, G. (2013) pH-dependent disruption of Escherichiacoli ATCC 25922 and model membranes by the human antimicrobial peptides hepcidin 20 and 25, FEBS J. 280, 2842-2854. 
[116] McDonald, M., Mannion, M., Pike, D., Lewis, K., Flynn, A., Brannan, A. M., Browne, M. J., Jackman, D., Madera, L., Coombs, M. R. P., Hoskin, D. W., Rise, M. L., and Booth, V. (2015) Structure-function relationships in histidine-rich antimicrobial peptides from Atlantic cod, Biochim. Biophys. Acta 1848, 1451-1461.

[117] Lehrer, R. I., Andrew Tincu, J., Taylor, S. W., Menzel, L. P., and Waring, A. J. (2003) Natural Peptide Antibiotics from Tunicates: Structures, Functions and Potential Uses, Integr. Comp. Biol. 43, 313-322.

[118] Arnusch, C. J., Albada, H. B., van Vaardegem, M., Liskamp, R. M. J., Sahl, H.-G., Shadkchan, Y., Osherov, N., and Shai, Y. (2012) Trivalent Ultrashort Lipopeptides are Potent pH Dependent Antifungal Agents, J. Med. Chem. 55, 1296-1302.

[119] Kacprzyk, L., Rydengard, V., Morgelin, M., Davoudi, M., Pasupuleti, M., Malmsten, M., and Schmidtchen, A. (2007) Antimicrobial activity of histidine-rich peptides is dependent on acidic conditions, Biochim. Biophys. Acta. 1768, 2667-2680.

[120] Makovitzki, A., and Shai, Y. (2005) pH-Dependent antifungal lipopeptides and their plausible mode of action, Biochemistry 44, 9775-9784.

[121] Mason, A. J., Gasnier, C., Kichler, A., Prevost, G., Aunis, D., Metz-Boutigue, M.-H., and Bechinger, B. (2006) Enhanced membrane disruption and antibiotic action against pathogenic bacteria by designed histidine-rich peptides at acidic $\mathrm{pH}$, Antimicrob. Agents Chemother. 50, 3305-3311.

[122] Goessler-Schoefberger, R., Hesser, G., Muik, M., Wechselberger, C., and Jilek, A. (2009) An orphan dermaseptin from frog skin reversibly assembles to amyloid-like aggregates in a pH-dependent fashion, FEBS J. 276, 5849-5859.

[123] Becucci, L., Valensin, D., Innocenti, M., and Guidelli, R. (2014) Dermcidin, an anionic antimicrobial peptide: influence of lipid charge, $\mathrm{pH}$ and $\mathrm{Zn}^{2+}$ on its interaction with a biomimetic membrane, Soft Matter 10, 616-626.

[124] Wang, K., Yan, J., Chen, R., Dang, W., Zhang, B., Zhang, W., Song, J., and Wang, R. (2012) Membrane-Active Action Mode of Polybia-CP, a Novel Antimicrobial Peptide Isolated from the Venom of Polybia paulista, Antimicrob. Agents Chemother. 56, 3318-3323.

[125] Carnicelli, V., Lizzi, A. R., Ponzi, A., Amicosante, G., Bozzi , A., and Di Giulio, A. (2013) Interaction between antimicrobial peptides (AMPs) and their primary target, the biomembranes., In Microbial Pathogens and Strategies for Combating Them: Science, Technology and Education. (Méndez-Vilas, A., Ed.), pp 1123-1134., Formatex Research Center., Badajoz, Spain.

[126] Tamm, L. K. (2006) Protein-Lipid Interactions: From Membrane Domains to Cellular Networks, pp 97-115 Wiley, Weinheim Germany.

[127] Fernandez, D. I., Le Brun, A. P., Whitwell, T. C., Sani, M. A., James, M., and Separovic, F. (2012) The antimicrobial peptide aurein 1.2 disrupts model membranes via the carpet mechanism, Phys. Chem. Chem. Phys. 14, 15739-15751.

[128] Boland, M. P., and Separovic, F. (2006) Membrane interactions of antimicrobial peptides from Australian tree frogs, Biochim. Biophys. Acta. 1758, 1178-1183.

[129] Chen, R., and Mark, A. E. (2011) The effect of membrane curvature on the conformation of antimicrobial peptides: implications for binding and the mechanism of action, Eur. Biophys. J. 40, 545-553.

[130] Pan, Y. L., Cheng, J. T. J., Hale, J., Pan, J., Hancock, R. E. W., and Straus, S. K. (2007) Characterization of the structure and membrane interaction of the antimicrobial peptides aurein 2.2 and 2.3 from Australian southern bell frogs, Biophys. J. 92, 2854-2864. 
[131] Marcotte, I., Wegener, K. L., Lam, Y.-H., Chia, B. C. S., de Planque, M. R. R., Bowie, J. H., Auger, M., and Separovic, F. (2003) Interaction of antimicrobial peptides from Australian amphibians with lipid membranes, Chem. Phys. Lipids. 122, 107-120.

[132] Alves, D., and Pereira, M. O. (2014) Mini-review: Antimicrobial peptides and enzymes as promising candidates to functionalize biomaterial surfaces, Biofouling 30, 483-499.

[133] Zasloff, M. (2016) Antimicrobial Peptides: Do They Have a Future as Therapeutics? in Antimicrobial Peptides : Role in Human Health and Disease, pp. 147-154 Springer International Publishing.

[134] Xiao, H., Shao, F., Wu, M., Ren, W., Xiong, X., Tan, B., and Yin, Y. (2015) The application of antimicrobial peptides as growth and health promoters for swine, J. Anim. Sci. Biotechnol. 6, 1-12.

[135] Dostalova, S., Milosavljevic, V., Guran, R., Kominkova, M., Cihalova, K., Kopel, P., Vaculovicova, M., Adam, V., and Kizek, R. (2015) Antiviral activity of fullerenes modified with maximin H5 derivaties, Mendelnet 2015, 579-584.

[136] Fox, J. L. (2013) Antimicrobial peptides stage a comeback, Nature Biotechnology 31, 379382.

[137] Fjell, C. D., Hiss, J. A., Hancock, R. E., and Schneider, G. (2012) Designing antimicrobial peptides: form follows function, Nature reviews. Drug discovery 11, 37-51. 


\section{TABLES.}

Table 1. Conformational contributions to the secondary structure of MH5 in the presence of membranes formed from S. aureus lipid extracts.

\begin{tabular}{|l|l|l|l|l|}
\hline $\mathrm{pH}$ & $\begin{array}{c}\alpha \text {-helical structure } \\
(\%)\end{array}$ & $\begin{array}{r}\beta \text {-strands } \\
(\%)\end{array}$ & $\begin{array}{l}\beta \text {-turns } \\
(\%)\end{array}$ & $\begin{array}{l}\text { Unordered } \\
(\%)\end{array}$ \\
\hline 6 & $58 \pm 3.1$ & $17 \pm 3.1$ & $7 \pm 3.1$ & $18 \pm 3.1$ \\
\hline 7 & $54 \pm 1.0$ & $12 \pm 1.0$ & $1 \pm 1.0$ & $21 \pm 1.0$ \\
\hline 8 & $47 \pm 0.5$ & $25 \pm 0.5$ & $8 \pm 0.5$ & $21 \pm 0.5$ \\
\hline
\end{tabular}


Table 2: The compressibility modulus, $\mathrm{Cs}_{\mathrm{s}}^{-1} \mathrm{mN} \mathrm{m}^{-1}$, for lipid mimics of S. aureus membranes in the presence and absence of MH5 at varying $\mathrm{pH}$.

\begin{tabular}{|c|c|c|c|c|c|c|c|c|}
\hline & DOPG & $\mathrm{CL}$ & Lys- & DOPC & CL:Lys- & DPG in & molar & o 55:5:X \\
\hline & & & & $X=0$ & $X=20$ & $X=40$ & $X=60$ & $X=80$ \\
\hline $\mathrm{pH} 6$ & & & & & & & & \\
\hline - MH5 & 70.14 & 39.23 & 49.47 & 33.02 & 35.78 & 41.45 & 46.92 & 49.71 \\
\hline+ MH5 & 99.67 & 40.15 & 85.18 & 69.83 & 104.91 & 108.27 & 109.94 & 117.08 \\
\hline $\mathrm{pH} 7$ & & & & & & & & \\
\hline - MH5 & 45.27 & 28.12 & 38.11 & 31.06 & 32.92 & 36.07 & 38.06 & 45.03 \\
\hline+ MH5 & 61.49 & 43.54 & 74.92 & 33.68 & 36.76 & 43.54 & 63.82 & 74.92 \\
\hline $\mathrm{pH} 8$ & & & & & & & & \\
\hline - MH5 & 36.60 & 27.70 & 26.51 & 25.24 & 28.77 & 30.76 & 32.69 & 34.33 \\
\hline + MH5 & 36.43 & 53.47 & 47.5 & 29.02 & 30.73 & 32.51 & 34.92 & 37.68 \\
\hline
\end{tabular}

Monolayers were formed from either, DOPG, CL, Lys-DOPG or DOPG:CL:Lys-DOPG in the molar ratio 55:5: $\mathrm{X}$ where $\mathrm{X}=0,20,40,60$ or 80 , as described above. These data show that $\mathrm{pH}$ and the presence of both Lys-DOPG and MH5 influence the rigidity and lipid-packing characteristics of lipid mimics of $S$. aureus membranes, as discussed in the text. In relation to physiological levels of Lys-PG in membranes of S. aureus, in the absence of MH5, the $\mathrm{C}_{\mathrm{s}}^{-1}$ of monolayers were 36.07 $\mathrm{mN} \mathrm{m}^{-1}(\mathrm{X}=40)$ at $\mathrm{pH} 7$ and $42.92 \mathrm{mN} \mathrm{m}^{-1}(\mathrm{X}=60)$ at $\mathrm{pH} 6$, indicating that the latter monolayers were more rigid and possessed relatively denser lipid packing than the former monolayers (Table II). The presence of MH5 led to increases in the $\mathrm{C}_{s}^{-1}$ of both these monolayers, which were 43.54 $\mathrm{mN} \mathrm{m}^{-1}(\mathrm{X}=40)$ at $\mathrm{pH} 7$ and 109.94 at $\mathrm{mN} \mathrm{m}^{-1}(\mathrm{X}=60)$. These latter results indicate that the presence of MH5 increased the rigidity and lipid packing density of both monolayers, which is consistent with the peptide partitioning into these membranes. Moreover, this effect was of the order of ten-fold greater at $\mathrm{pH} 6$ (change in $\mathrm{C}_{\mathrm{s}}^{-1}$ of 63.02) as compared to $\mathrm{pH} 7$ (change in $\mathrm{C}_{\mathrm{s}}{ }^{-1}$ of 7.47), indicating that the ability of MH5 to partition into membranes of $S$. aureus is strongly enhanced by the low $\mathrm{pH}$ conditions that are optimal for the growth of the organism (Table 2). Values of $\mathrm{C}_{\mathrm{s}}^{-1}$ were determined in quadruplicate and the mean value derived, as described above. 


\section{FIGURE CAPTIONS}

Figure 1. Primary structure analysis of MH5. (A) The peptide was analysed according to hydrophobic moment plot methodology, which yielded values of 0.44 and 0.29 for $<\mu_{\mathrm{H}}>$ and $<$ $\mathrm{H}>$ respectively. Values of $<\mu_{\mathrm{H}}>$ with this order of magnitude are generally indicative of the potential to form $\alpha$-helical structure in an anisotropic environment with activity at an aqueous or membrane interface ${ }^{66}$. Using $<\mu_{\mathrm{H}}>$ and $<\mathrm{H}>$, MH5 was plotted on the extended hydrophobic moment plot diagram ${ }^{53}$ and yielded a data point in the area indicating the potential to form a tilted peptide (blue area) with similar parameters to HA2, a known tilted peptide (Figure 1A). HA2 and other tilted peptides possess a hydrophobicity gradient along the $\alpha$-helical long axis, which causes the $\alpha$-helix to penetrate membranes at a shallow angle thereby disturbing membrane lipid organisation and compromising bilayer integrity ${ }^{14,67-71}$. (B) To characterise the potential tilted peptide formed by MH5, amphiphilic profiling analysis was undertaken, which essentially visualises potential hydrophobicity gradients via plots of $-<\mu_{\mathrm{H}}>$ along a peptide’s sequence ${ }^{72}$. This analysis revealed that MH5 possessed a strong hydrophobicity gradient, which decreased in the direction of the $\mathrm{N}$ terminus to the $\mathrm{C}$ terminus and extended over most of the peptide's primary structure (Figure 1B). (C) MH5 was represented as a two-dimensional axial projection, assuming a residue periodicity of $100^{\circ}{ }^{54}$, and showed well defined amphiphilicity (Figure 1C). Consistent with the ability to form a tilted peptide, this $\alpha$-helix possesses a wide apolar face, which is predominantly formed from strongly hydrophobic residues such as leucine, isoleucine and valine. The $\alpha$-helix possesses a narrower polar face, which includes multiple glycine residues and is strongly anionic due the presence of a triplet of aspartic acid residues. These residues, D11, D14 and D15 (shown in blue), essentially define the polar face of the MH5 $\alpha$-helix and are centrally clustered in relation to the long axis of this $\alpha$-helix. The long axis of the $\alpha$-helix is demarked at the 
C-terminus and N-terminus, respectively, by the residues I1 and L20, which each carry an amide moiety (Figure 1C). Also shown in Figure 1C is a two-dimensional axial projection of the HA2 peptide, which forms a $\alpha$-helix with structural similarities to that of MH5, including a wide apolar face formed from strongly hydrophobic residues and a narrower polar face, which possesses multiple glycine residues and is strongly anionic due the presence of glutamic acid and aspartic acid residues (E11, E15 and D19, shown in blue) (Figure 1C).

Figure 2. The surface activity of MH5. (A) MH5 was investigated for activity at an air / buffer interface at pH 6 (dotted grey), $\mathrm{pH} 7$ (black) and pH 8 (grey). Across this pH range, the surface activity of the peptide was very similar, increasing rapidly up to MH5 concentrations of $2 \mu \mathrm{M}$ and inducing maximal surface pressure changes of circa $28 \mathrm{mN} \mathrm{m}^{-1}$. At MH5 concentrations above 2 $\mu \mathrm{M}$, the surface pressure of these peptide monolayers became independent of MH5 concentration, indicating that air / buffer interface was saturated with molecules of the peptide. (B) The orientation of $\mathrm{MH} 5$ at an air / buffer interface was investigated using compression isotherms at $\mathrm{pH}$ 6 (dotted grey), pH 7 (black) and pH 8 (grey), which had a generally sigmoidal shape indicative that MH5 forms stable monolayers ${ }^{18,22}$. Across this $\mathrm{pH}$ range, these monolayers showed collapse surface pressures ranging between 26.8 and $24.1 \mathrm{mN} \mathrm{m}^{-1}$, indicating the presence of well-ordered peptide films. The corresponding surface areas per molecule of MH5 ranged from 1.9 to $1.6 \mathrm{~nm}^{2}$, which is consistent with the peptide in an $\alpha$-helical conformation, orientated perpendicular to the interface $^{77}$. The extrapolated areas at $\Pi=0 \mathrm{mN} \mathrm{m}^{-1}$ for these isotherms ranged between 4.5 and $4.1 \mathrm{~nm}^{2}$ at $\mathrm{pH} 6,7$ and 8, consistent with the peptide in an $\alpha$-helical conformation orientated parallel to the air / buffer interface ${ }^{79}$. In all cases, experiments were performed at room temperature $\left(20^{\circ} \mathrm{C}\right)$, repeated in quadruplicate and the mean value taken. 


\section{Figure 3. The secondary structure of MH5 in the presence of membranes formed from $S$.}

aureus lipid extracts. SUVs were formed from lipid extracts of S. aureus, as described above, and CD analysis used to determine the secondary structure of MH5 in the presence of these lipid bodies at pH 6 (dotted grey), pH 7 (black) and pH 8 (grey). The resulting CD spectra showed minima at 221 - 222 and $209-210 \mathrm{~nm}$, which is indicative of $\alpha$-helical structure in MH5 (Table 1). The levels of this structure were around $48 \%$ at $\mathrm{pH}$, which increased by around $10 \%$ as $\mathrm{pH}$ was decreased to $\mathrm{pH} 6$, clearly showing that the ability of MH5 to adopt $\alpha$-helical structure is enhanced by low pH (Table 1). In all cases, $\mathrm{CD}$ experiments were conducted at $20{ }^{\circ} \mathrm{C}$, performed in quadruplicate and the mean value derived.

Figure 4. SUVs were formed from lipids and lipid mixtures, as described above, and CD analysis used to determine the secondary structure of MH5 in the presence of these lipid bodies across a range of pH. In all cases, the resulting CD spectra showed minima at 221 - 222 and $209-210 \mathrm{~nm}$, indicative of $\alpha$-helical structure in MH5. (A) shows typical examples of these spectra for MH5 at pH 7 and in the presence of DOPG (Red), CL (blue), LysylPG (green) and DOPG:CL:LysylPG in the molar ratio 55:5:X where $X=10$ (purple), 20 (dotted dark grey), 30 (dotted orange), 40 (dashed light blue), 50 (dashed black), 60 (dashed light grey) and 70 (dotted dark blue). (B) shows levels of $\alpha$-helical structure in MH5, which were determined as described above, for $\mathrm{pH} 6$ (black crosses), 7 (dark grey crosses) and 8 (light grey crosses), in the presence of DOPG:CL:LysylPG in the molar ratio 55:5: $\mathrm{X}$ where $\mathrm{X}=20,40,60,80$ or 100 . At each $\mathrm{pH}$ studied, MH5 was predominantly $\alpha$-helical and possessed similar levels of this structure for all values of X. However, for a given level of X, a statistically significant difference in levels of MH5 $\alpha$-helicity was observed as $\mathrm{pH}$ was varied (Figure 4B), decreasing from $\operatorname{circa} 50 \%$ at $\mathrm{pH} 6$ to $\operatorname{circa} 40 \%$ at $\mathrm{pH} 8$ [F = 98.376; $\mathrm{p}=0.001]$. In relation to physiological levels of LysPG in membranes of S. aureus, MH5 
possessed levels of $\alpha$-helicity of circa $45 \%$ at pH $7(\mathrm{X}=40)$, which increased to $50 \%$ at pH 6 (X $=60$ ). In all cases, $\mathrm{CD}$ experiments were conducted at $20{ }^{\circ} \mathrm{C}$, performed in quadruplicate and the mean value derived. Error bars represent standard deviations.

Figure 5. The interactions of MH5 with lipid mimics of $S$. aureus membranes. Lipid monolayers mimetic of $S$. aureus membranes were constructed, as described above, and the interaction of MH5 with these monolayers at constant area investigated. (A) shows the time course for interactions of the peptide with monolayers derived from lipid extracts of $S$. aureus membranes at pH 6 (black), pH 7 (dark grey) and pH 8 (light grey). At pH 7 and pH 8, MH5 partitioned into these monolayers, inducing maximal surface pressure changes of circa $4.0 \mathrm{mN} \mathrm{m}^{-1}$ to $3.5 \mathrm{mN} \mathrm{m}^{-1}$ over 400 secs. However, at pH 6, MH5 induced maximal surface pressures in monolayers of the order of $8.0 \mathrm{mN} \mathrm{m}^{-1}$ over 120 secs, clearly showing that the ability of the peptide to partition into lipid mimics of S. aureus membranes monolayers was enhanced by low pH (Figure 5A). (B) shows the interaction of MH5 with monolayers formed from DOPG:CL:Lys-DOPG in the molar ratio 55:5:X where $\mathrm{X}=0,20,40,60,80$ or 100, at pH 6 (black crosses), 7 (dark grey crosses) and 8 (light grey crosses). For each $\mathrm{pH}$ studied, regression analysis indicated a strong negative correlation between $\mathrm{X}$ and the maximal pressure change induced by MH5 $\left(\mathrm{R}^{2}=0.97\right)$. These results show that the ability of MH5 to partition into these lipid mimics of S. aureus membranes is influenced by their Lys-PG content and $\mathrm{pH}$, as discussed in the text. In relation to physiological levels of Lys-PG in membranes of S. aureus, MH5 induced maximal surface pressure changes of $5.6 \mathrm{mN} \mathrm{m}^{-1}$ at $\mathrm{pH} 7(\mathrm{X}=40)$, which increased to $6.2 \mathrm{mN} \mathrm{m}^{-1}$ at $\mathrm{pH} 6(\mathrm{X}=60)$ (Figure $\left.5 \mathrm{~B}\right)$. These results indicate that the ability of the peptide to partition into S. aureus membranes is enhanced by the low pH conditions that are optimal for the growth of the organism. Monolayer experiments 
were performed in quadruplicate and the mean value derived, as described above. Error bars represent standard deviations.

\section{Figure 6. Compression isotherm analysis of MH5 interactions with lipid mimics of S. aureus}

membranes. Lipid monolayers were constructed and compressed in the presence and absence of MH5 at varying $\mathrm{pH}$, as described above, to produce isotherms, which are denoted as follows: DOPG (solid black), CL (solid dark grey), Lys-DOPG (solid light grey), and DOPG:CL:LysDOPG in the molar ratio 55:5:X where $\mathrm{X}=0$ (black dotted dash), 20 (dark grey dotted), 40 (light grey dotted), 60 (dark grey dotted dash) or 80 (black dotted). Each measurement was performed in quadruplicate and the mean value derived, as described above. These isotherms were then used to derive values for $\mathrm{C}_{s}^{-1}$, the compressibility modulus (Table 2), and $\Delta \mathrm{G}_{\mathrm{mix}}$, the Gibbs free energy of mixing (Figure 7), of these experimental systems.

Figure 7. The Gibbs free energy of mixing for lipid mimics of $S$. aureus membranes. Compression isotherms were derived, as described above (Figure 6) and used to derive values for the Gibbs free energy of mixing, $\Delta \mathrm{G}_{\mathrm{mix}}$, at $20 \mathrm{mN} \mathrm{m}^{-1}$ for monolayers formed from DOPG:CL:LysDOPG in the molar ratio 55:5:X where X = 0 (black), 20 (dark grey), 40 (grey), 60 (white) or 80 (light grey) in the absence (solid) and presence (diagonals) of MH5. These data show that $\mathrm{pH}$ and the presence of both Lys-DOPG and MH5 influence the thermodynamic stability of lipid mimics of $S$. aureus membranes, as discussed in the text. In relation to physiological levels of Lys-PG in membranes of S. aureus, in the absence of MH5, the $\Delta \mathrm{G}_{\text {mix }}$ of monolayers were $-2.0(\mathrm{X}=40)$ at $\mathrm{pH} 7$ and $-5.0(\mathrm{X}=60)$ at $\mathrm{pH}$ 6, indicating that the latter monolayers were thermodynamically more stable than the former monolayers. The presence of MH5 led to increases in the $\Delta \mathrm{G}_{\text {mix }}$ values of both these monolayers, which were $-3.0(\mathrm{X}=40)$ at $\mathrm{pH} 7$ and $-8.0(\mathrm{X}=60)$. These latter results indicate that the presence of MH5 increased the thermodynamic stability of both monolayers and 
that this effect was of the order of three-fold greater at $\mathrm{pH} 6$ (change in $\Delta \mathrm{G}_{\text {mix }}$ of -1 ) as compared to $\mathrm{pH} 7$ (change in $\Delta \mathrm{G}_{\text {mix }}$ of -3). These results show that the ability of MH5 to increase the thermodynamic stability of membranes of $S$. aureus is strongly enhanced by low $\mathrm{pH}$ conditions that are optimal for the growth of the organism. Values of $\Delta \mathrm{G}_{\text {mix }}$ were determined in quadruplicate and the mean value derived, as described above. Error bars represent standard deviations.

Figure 8. The lysis of vesicles formed from lipid extracts of $S$. aureus membranes by MH5. Calcein was entrapped in vesicles formed from $S$. aureus membrane lipids and the levels of the dye released by MH5 used to calculate the \% lysis induced by the peptide at pH 6 (black crosses), pH 7 (dark grey crosses) and pH 8 (light grey crosses). At each pH studied, the peptide induced the release of calcein from these vesicles with the level of the dye released increasing as the concentration of MH5 became progressively higher, showing that MH5 was generally membranolytic to these membranes. At MH5 concentrations of circa $500 \mu \mathrm{M}$, the release of calcein from these vesicles became independent of peptide concentration, indicating that membranes were saturated with MH5 and levels of dye release were maximal, ranging from 40.3 $\%$ at $\mathrm{pH} 8$ to $72.6 \%$ at $\mathrm{pH}$ 6. It was also found that the levels of lysis induced by the peptide were enhanced by increasing $\mathrm{pH}$, for example, at the MIC of MH5 for S. aureus, levels of dye release induced by the peptide were circa $30 \%$ at pH 8 but rose to $57 \%$ at $\mathrm{pH}$. Values of the \% lysis were determined in quadruplicate and the mean value derived, as described above.

Figure 9. The lysis of vesicles formed from mixtures of PG, CL and Lys-DOPG by MH5. Calcein was entrapped in vesicles formed DOPG:CL:Lys-DOPG in the molar ratio 55:5:X where $X=0,20,40,60$ and 80 and 100, and the levels of the dye released by MH5 used to calculate the 
\% lysis induced by the peptide at pH 6 (Figure 9A), pH 7 (Figure 9B) and pH 8 (Figure 9C) for $X=0$ (black cross), $X=20$ (dark grey cross), $X=40$ (black dotted circles), $X=60$ (light grey dotted circles), $\mathrm{X}=80$ (dark grey dotted circles) or $\mathrm{X}=100$ (light grey crosses). These plots show that the membranolytic action of MH5 generally exhibited kinetics that were similar to the Michaelis-Menten-type kinetics of lytic AMPs that utilise 'Carpet'-like mechanisms in their antimicrobial action ${ }^{74,76,80}$. These kinetics were characterized by $K_{m}$ values, which provides an inverse measure of the lipid affinity of the peptide, along with $E_{\max }$ values, which represent the lytic efficiency of MH5. It was found that maximal levels of lysis and the lipid affinity of the peptide for a given Lys-DOPG concentration were highest at pH 6 and generally decreased with increasing $\mathrm{pH}$. For example, at $\mathrm{X}=20$ and an MH5 concentration of $250 \mu \mathrm{M}$, the maximal levels of calcein released by the peptide, $\mathrm{E}_{\max }$, increased from $\operatorname{circa} 58.0 \%$ at $\mathrm{pH} 8$ to $73.0 \%$ at $\mathrm{pH} 6$ (Figures 9A, 9b and 9C). For the same lytic curve, $\mathrm{K}_{\mathrm{m}}$ decreased from $45 \mu \mathrm{M}$ at $\mathrm{pH} 8$ to $38 \mu \mathrm{M}$ at $\mathrm{pH}$ 6, indicating an increase in the lipid affinity of the peptide (Figures 9A and 9C). In addition to $\mathrm{pH}$, these results also show that the concentration of MH5 and the presence of Lys-DOPG influence the ability of MH5 to lyse lipid mimics of S. aureus membranes, as discussed in the text. Figure 9D, which was derived from Figures 9A, 9B and 9C, shows the \% lysis induced by MH5 at its MIC of $90 \mu \mathrm{M}$ in vesicles formed DOPG:CL:Lys-DOPG in the molar ratio 55:5:X with varying $\mathrm{X}$ at pH 6 (black crosses), pH 7 (dark grey crosses) and pH 8 (light grey crosses). At the physiological levels of Lys-PG found in membranes of $S$. aureus, MH5 induced levels of lysis of circa $40 \%(\mathrm{X}=40)$ at $\mathrm{pH} 7$, which rose to $48 \%(\mathrm{X}=60)$ at $\mathrm{pH} 6$, indicating that the ability of the peptide to lyse membranes of the organism is strongly enhanced by the low pH conditions that are optimal for its growth (Figure 9D). In all cases, values of the \% lysis were determined in quadruplicate and the mean value derived, as described above. 
Figure 10. The haemolytic properties of MH5. Washed ovine erythrocytes were incubated with MH5 and the \% lysis of these erythrocytes monitored by the absorbance of haemoglobin release at pH 6 (blue), pH 7 (red) and pH 8 (green). In each case, the peptide showed similar kinetics with haemolysis increasing up to MH5 concentrations of circa $1000 \mu \mathrm{M}$ and then becoming independent of peptide concentration. Levels of haemolysis were generally very low (> $2 \%)$ and increased with decreasing $\mathrm{pH}$. At the MIC of MH5, the \% lysis induced by the peptide varied between $1.6 \%$ at $\mathrm{pH} 6$ and $1.2 \%$ at $\mathrm{pH}$ 8. Values of the \% haemolysis were determined in quadruplicate and the mean value derived, as described above. 


\section{Figure 1}

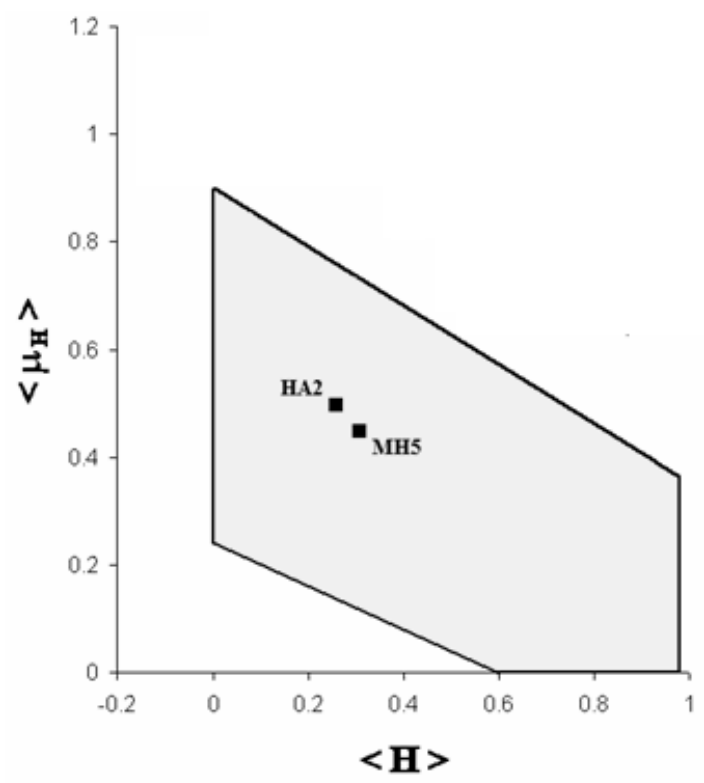

A

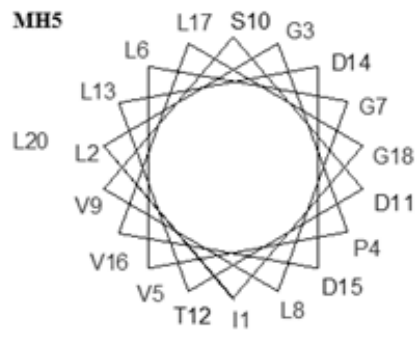

119
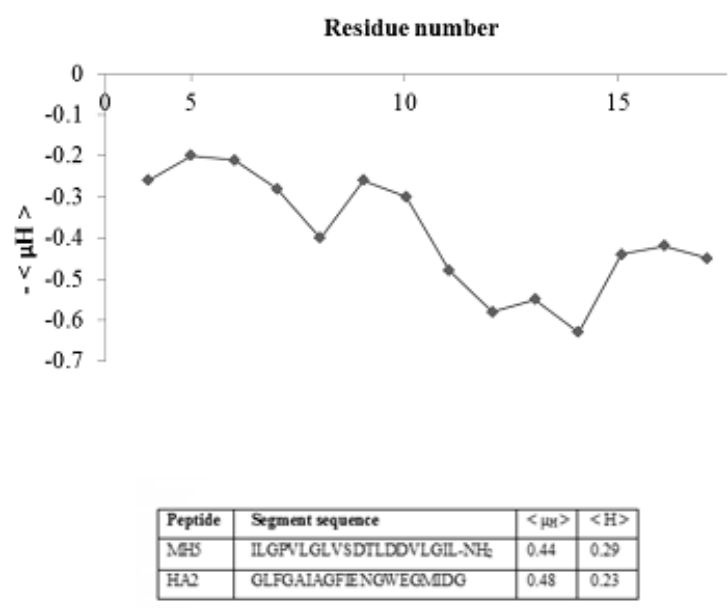

B

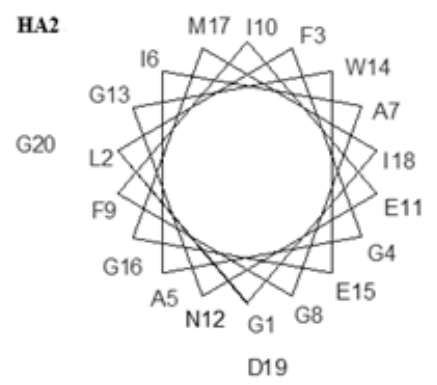

C 


\section{Figure 2}

A
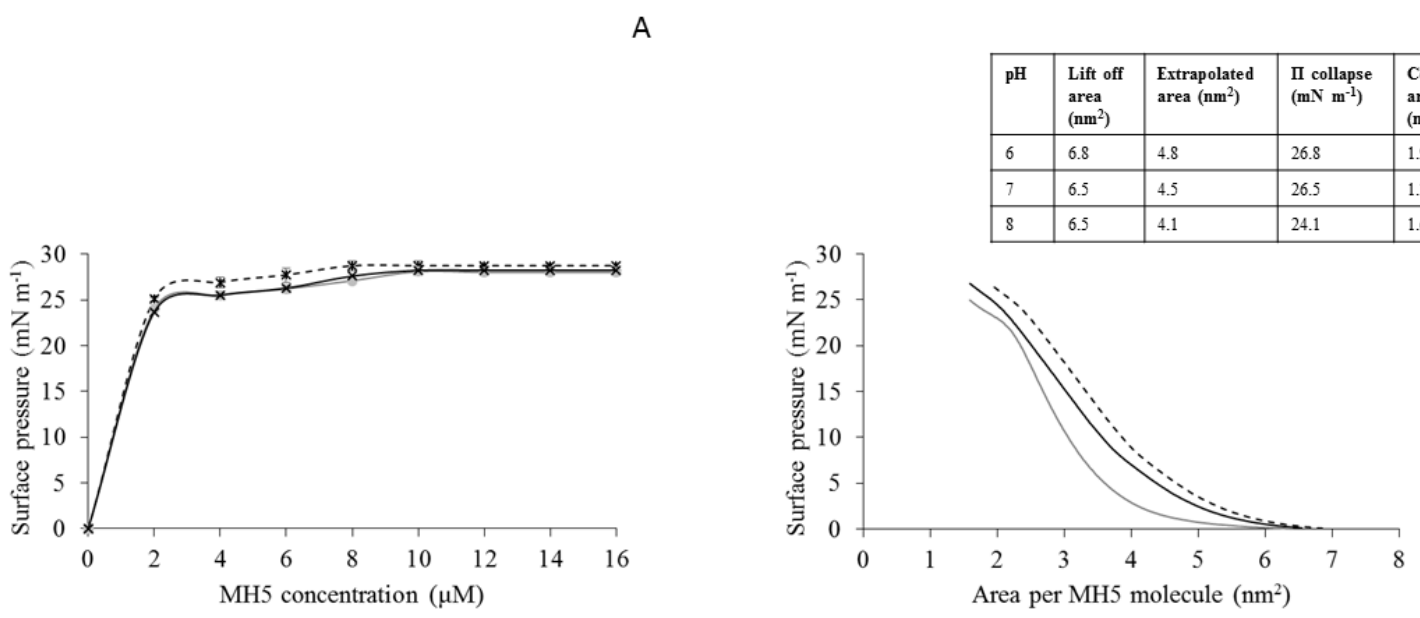


\section{Figure 3}

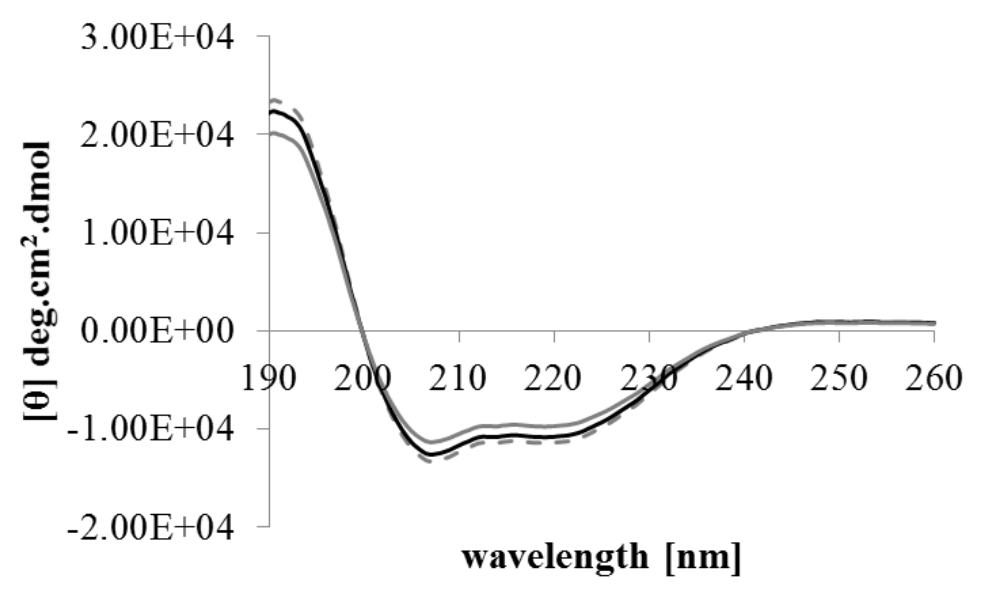




\section{Figure 4}
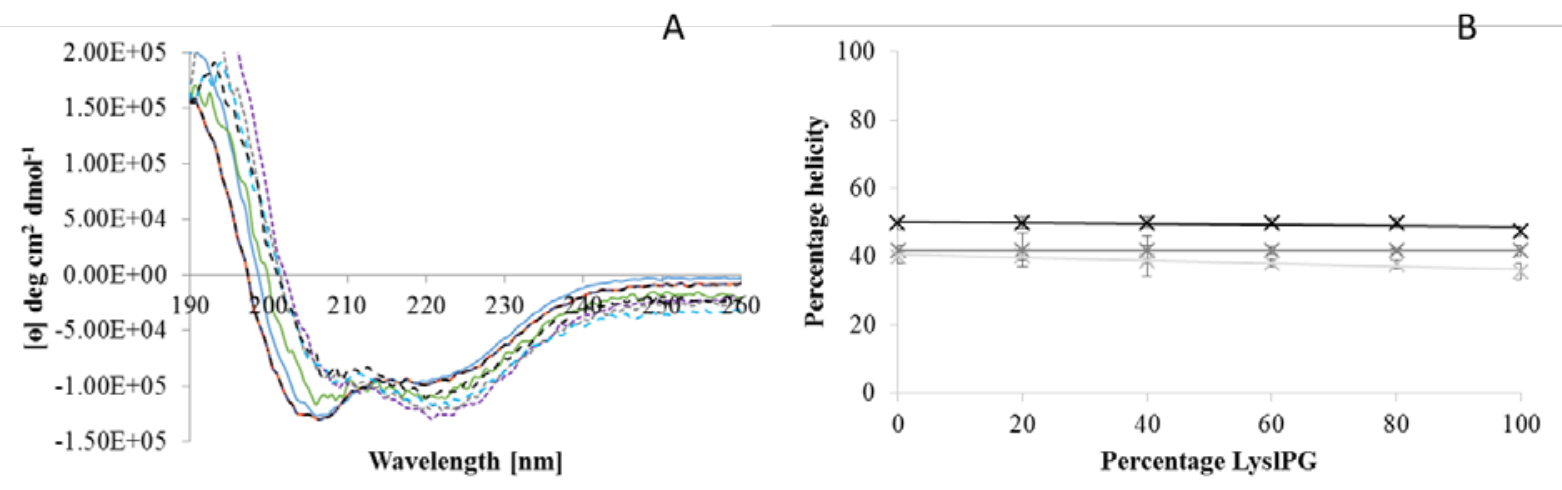


\section{Figure 5}
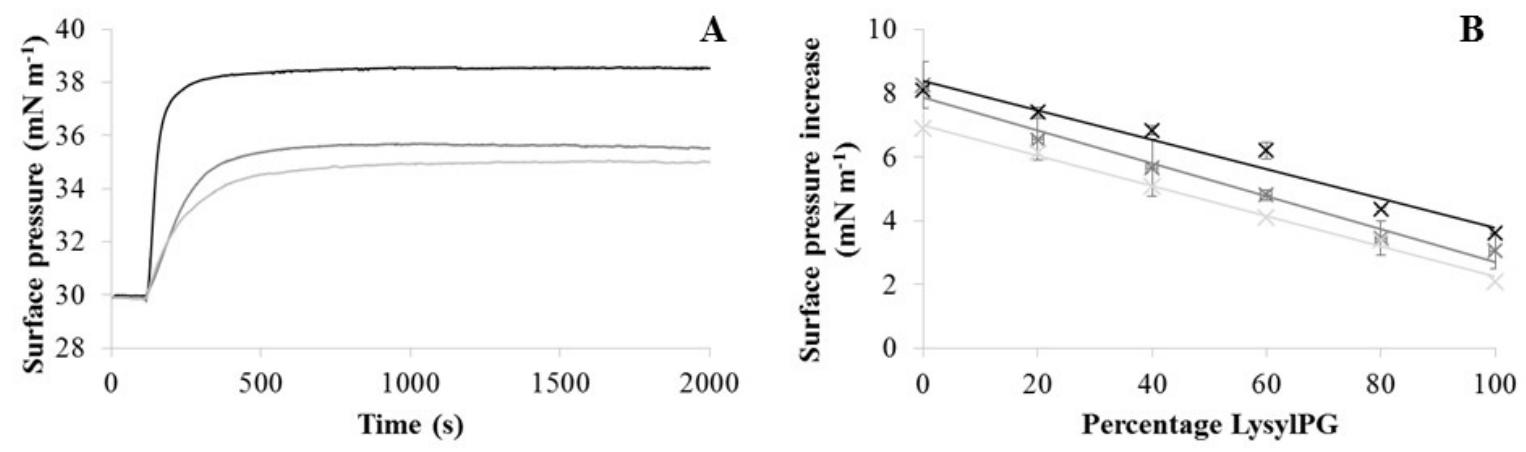


\section{Figure 6}
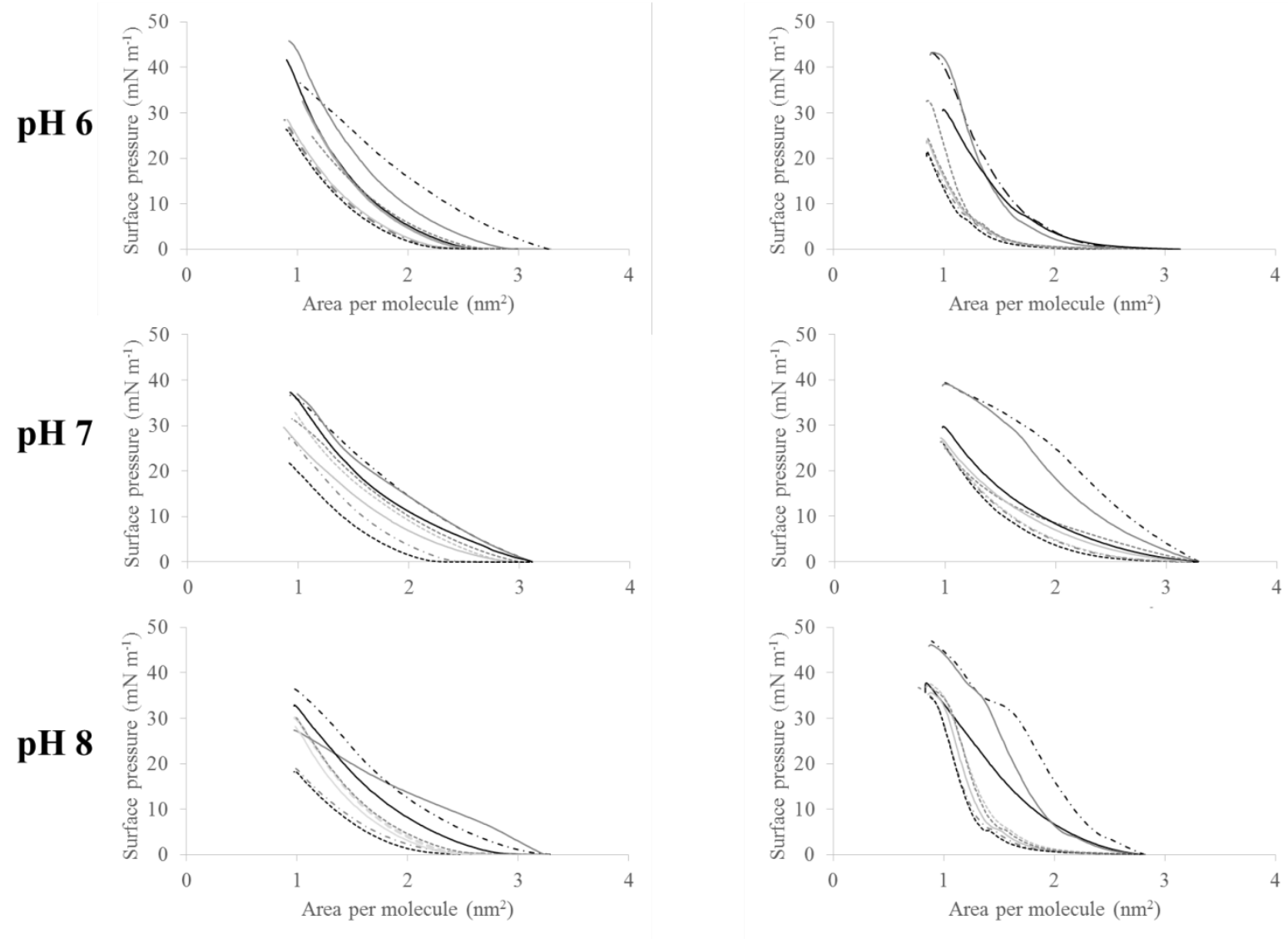

Absence of MH5

Presence of MH5 


\section{Figure 7}

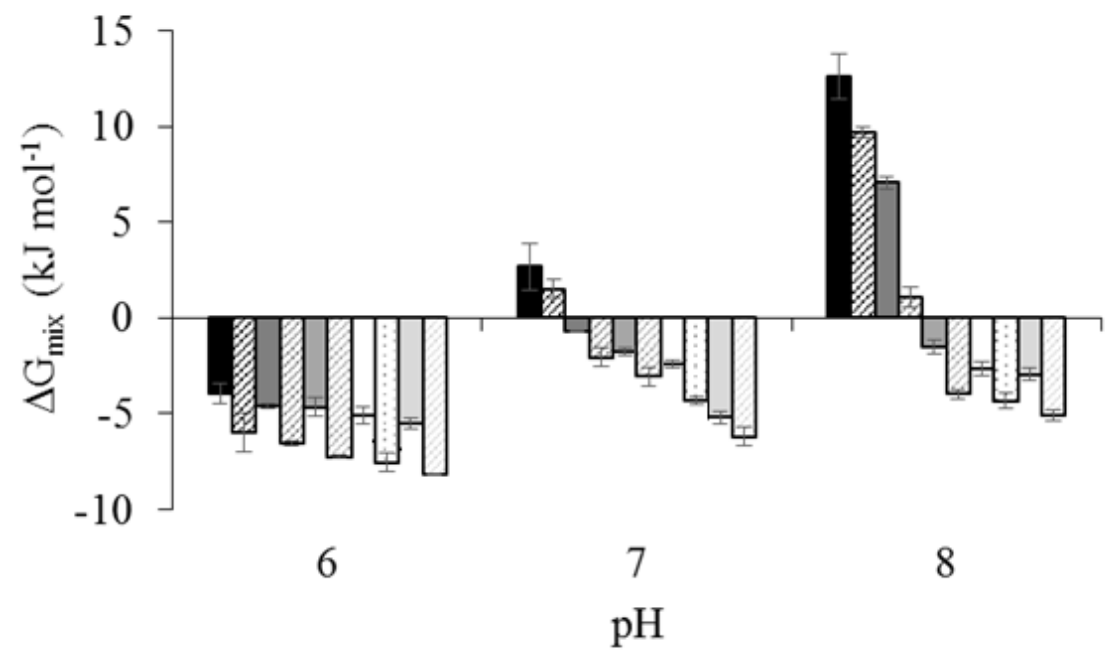


Dennison et al. 2016. Biochemistry DOI: 10.1021/acs.biochem.6b00101

\section{Figure 8}

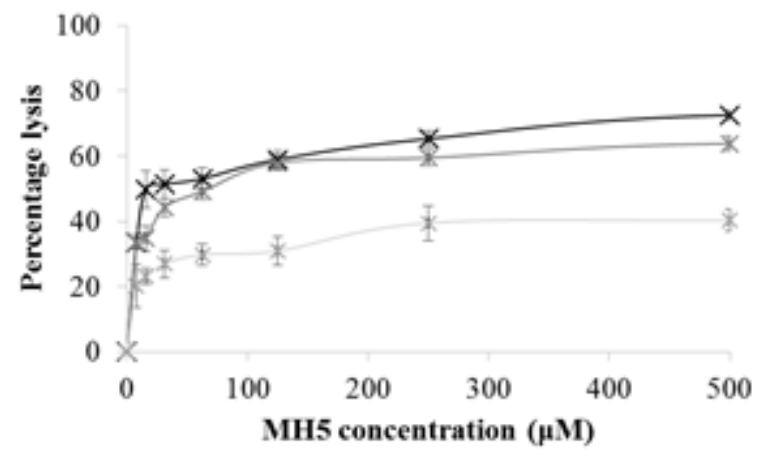




\section{Figure 9}
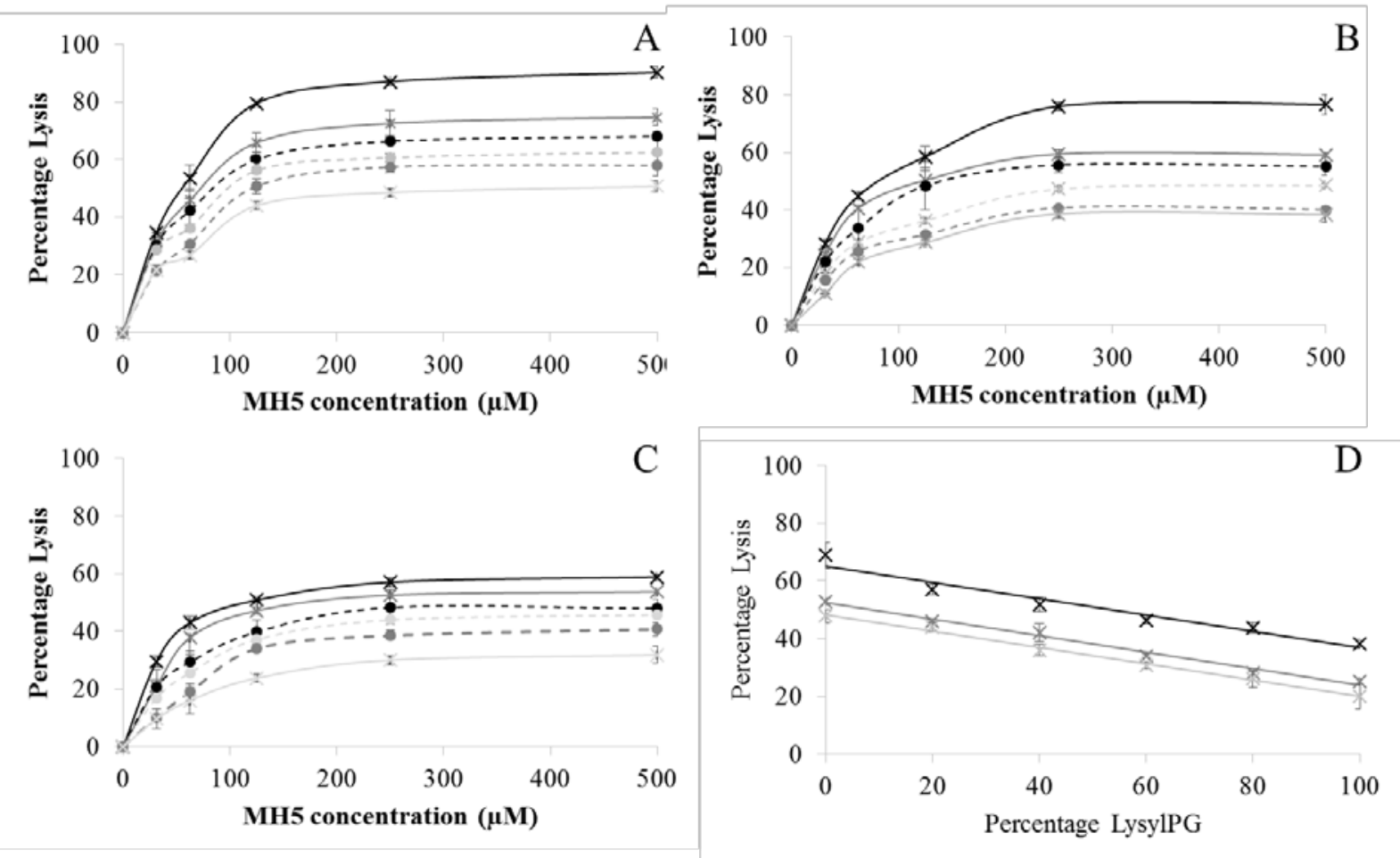


\section{Figure 10}

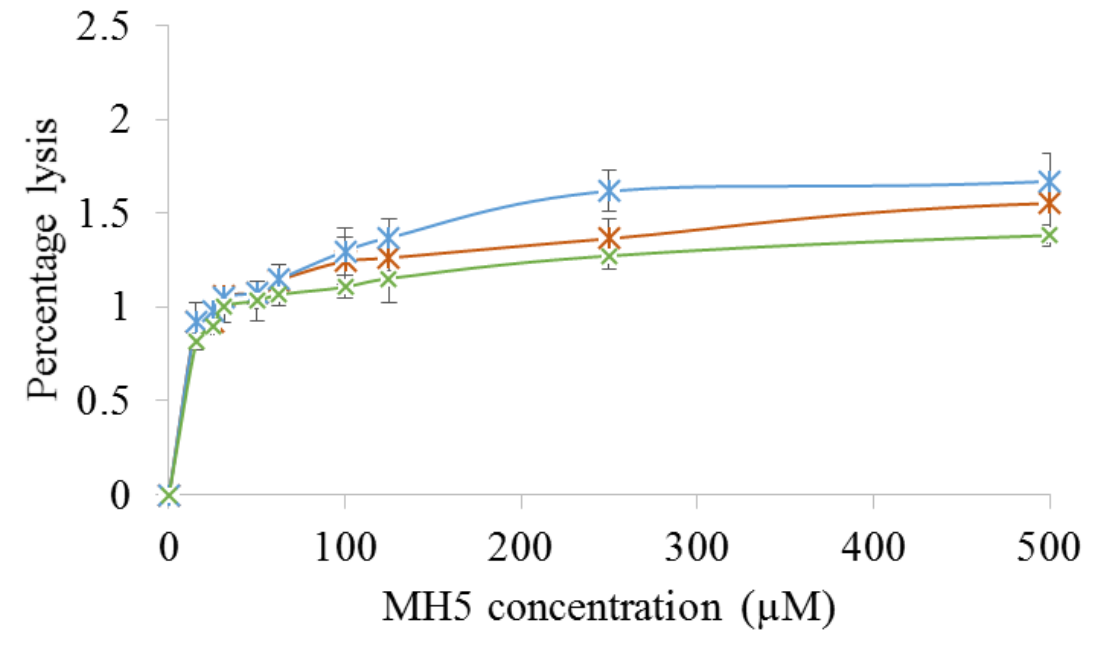




\section{Insert Table of Contents Graphic and Synopsis Here}

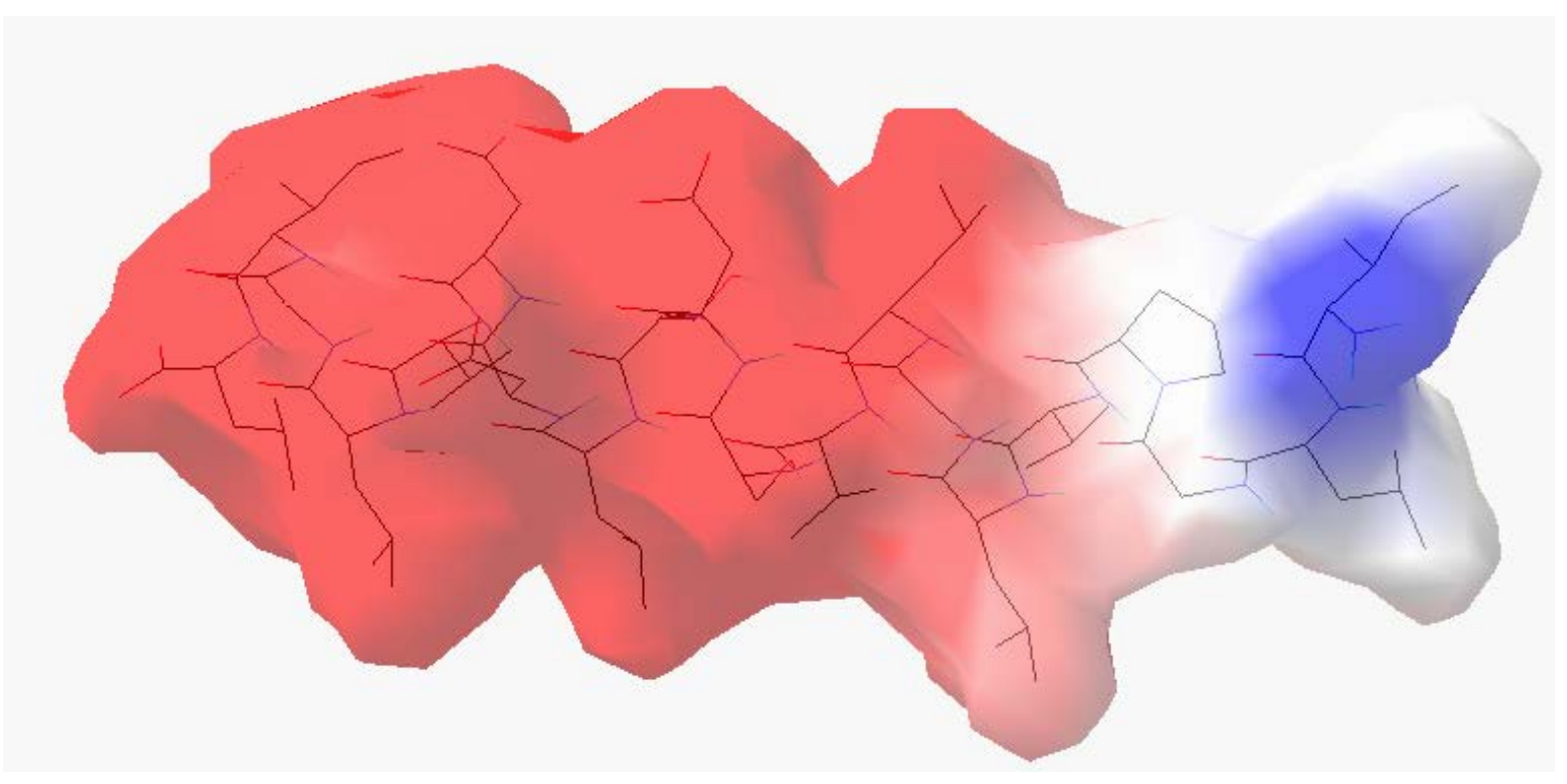

